\title{
Population structure of the parasitic nematode Anguillicola crassus, an invader of declining North Atlantic eel stocks
}

\author{
SÉBASTIEN WIELGOSS, ${ }^{*}$ HORST TARASCHEWSKI,† AXEL MEYER* and THIERRY WIRTH† \\ *Lehrstuhl für Zoologie und Evolutionsbiologie, Fachbereich Biologie, Universität Konstanz, 78457 Konstanz, Germany, \\ †Zoologisches Institut I, Ökologie-Parasitologie, Universität Karlsruhe, Kornblumenstraße 13, 76128 Karlsruhe, Germany, \\ $\ddagger$ Ecole Pratique des Hautes Etudes, Département Systématique et Evolution, Muséum National d’Histoire Naturelle, 16 Rue Buffon, \\ 75005 Paris, France
}

\begin{abstract}
Probably half of all animal species exhibit a parasitic lifestyle and numerous parasites have recently expanded their distribution and host ranges due to anthropogenic activities. Here, we report on the population genetic structure of the invasive nematode Anguillicola crassus, a parasite in freshwater eels, which recently spread from Asia to Europe and North America. Samples were collected from the newly colonized naïve host species Anguilla anguilla (Europe) and Anguilla rostrata (North America), and from indigenous Anguilla japonica in Taiwan and Japan. Using seven microsatellite loci and one mitochondrial marker, we show that the parasite's population structure in Europe mirrors the zoogeographic Boreal-Lusitanian break along the English Channel. Both the north-to-south decline of nuclear allelic diversity and the loss of private alleles in the same direction are consistent with a significant isolation-by-distance pattern based on $\rho_{\mathrm{ST}}$ values. In combination with the specific topology of the distance tree among nematode populations, our data suggest that Europe was invaded only once from Taiwan, and that subsequently, genetic diversity was lost due to random drift. On the contrary, the North American sample shares distinct nuclear and mitochondrial signatures with Japanese specimens. We propose that the genetic structure in Europe was shaped by long-range anthropogenic eel host transfers in the north and a single dispersal event into the southwest. The genetically distinct Brittany sample at the edge of the Boreal-Lusitanian boundary is indicative of natural dispersal of fish hosts since recruitment occurs naturally there and invertebrate host dissemination is interrupted due to oceanic currents.
\end{abstract}

Keywords: Anguillicola crassus, freshwater eel, invasive species, microsatellites, population genetic structure

\section{Introduction}

Human-mediated global transfer of organisms, either shipped intentionally as live stock, or as blind passengers inside a carrying vector, has resulted in an unprecedented number of translocations, approaching half a million species (Pimentel et al. 2001). The subsequent establishment of

Correspondence: Axel Meyer, Fax: +49 753188 3018; E-mail: axel.meyer@uni-konstanz.de or Thierry Wirth, Fax: + 3314079 8036; E-mail: wirth@mnhn.fr alien species has resulted in far-reaching economic and ecological impacts on the affected biocoenoses (Sakai et al. 2001; Pimentel 2002; Cox 2004). Studies on the evolutionary aspects of invasions (see Lee 2002 for a review) are needed for both a comprehensive understanding of invasion biology and the elaboration of adequate management strategies against introduction and dispersal of economically important alien species. According to Colautti \& MacIsaac (2004), an invasion should be regarded as the final of five stages leading to a widespread occurrence of a species following a human-mediated range-jump, in which the newly established population must become a dominant part of the ecosystem. 
In this sense, not all successful colonizations can be regarded as (completed) invasions.

More than $50 \%$ of all animal species are assumed to be parasitic in lifestyle (Bush et al. 2001). Despite their huge diversity, parasites are under-represented in the evolutionary biology literature (Criscione et al. 2005) and studied systems comprising parasitic invaders remain scarce, although numerous parasites have rapidly expanded their ranges (Taraschewski 2006). For parasites, it has been suggested that host movement is one of the most decisive forces shaping population structure, acting by accelerated gene flow over large distances (Blouin et al. 1995; McCoy et al. 2003; Criscione \& Blouin 2004). However, in comparing the informativeness of neutral markers of both symbionts of a hostparasite system, Criscione et al. 2006 showed that population genetic structure was more pronounced in the trematode compared to its fish host. If this specific case was typical, then one might expect that with particular barriers to gene flow or differential selection regimes, parasite population structure might be established very rapidly after a successful invasion and within a few generations. Nuclear allele and genotype frequencies, as well as mitochondrial haplotype composition in the founding population(s) diverge from those of the donor environment, due to the action of genetic drift during the process of colonization (for a review refer to Sakai et al. 2001; Lee 2002; Cox 2004). Phenotypic changes as a response to differing biotic and abiotic stressors in their new habitat coincide with rapid genetic changes. Furthermore, within decades and in response to selection, newly established alien species have rapidly evolved divergent life-history traits as known from introduced sockeye salmon (Hendry et al. 2000) and have strong impacts on the communities due to predation and parasitism. The selective effects of the invasive green crab on Mytilus edulis populations (Freeman \& Byers 2006) and the mite Varroa destructor on stocks of the European honey bee Apis mellifera (Licek et al. 2004) are well- documented examples.

In this study, we investigated population genetic aspects of a parasite-host system, in which the nematode parasite Anguillicola crassus was accidentally translocated from its Asian sources to Europe in the early 1980s. Despite earlier management warnings (Egusa 1979), an import of 35 tons of live Japanese eels (Anguilla japonica) to European aquaculture presumably facilitated the nematode's rapid range-jump (Koops \& Hartmann 1989). Neither the native final host, A. japonica, nor its East Asian intermediate hosts (copepods, ostracods) succeeded in establishing themselves in Europe (Taraschewski 2006). Today, the nematode is also found in eels on the North American East Coast (Anguilla rostrata; Barse et al. 2001) and in several imported and indigenous eel species on the remote Island of Reunion. The latter nematode population most likely stems from Europe (Sasal et al. 2008). A. crassus belongs to the family Anguillicolidae (Nematoda, Dracunculoidea) and parasitizes the swimbladder of fishes that belong to the genus Anguilla (Moravec \& Taraschewski 1988). Growing parasitological and epidemiological knowledge has fostered its consideration as a model organism for invasion biology (Taraschewski 2006). Interestingly, in the invasive populations of the new hosts, both the prevalence and the intensities of the parasite are much higher than in those of the naturally affected host $(A$. japonica; Münderle et al. 2006). This coincides with elevated survival, longevity and reproductive output of the parasite in the immunologically naïve novel eel hosts (Knopf 2006; Taraschewski 2006). A. crassus has an indirect life cycle that starts and ends in its anguillid final host's swimbladder lumen, where sexual reproduction takes place (see Kirk 2003 and references therein for a more detailed overview). Subsequently, whereas adult nematodes die, both eggs and hatched L2 larvae escape by extrusion into the gastrointestinal tract. After anal release, the hatched free-living larval stage of the parasite attaches to benthic substratum and undulates to attract predatory crustacean intermediate hosts of the benthic zone (Thomas \& Ollevier 1993). Upon ingestion, infected crustaceans display sluggish movement (Kirk et al. 2000a) and are assumingly preyed on by eel and other benthic fish predators, such as gobids and ruffe, in which the parasite cannot finish its life cycle but remains infective (Thomas \& Ollevier 1992). Larger piscivorous eels (> 20 cm; Tesch 2003) may acquire larval parasites mainly through these infected prey fish that serve as so-called paratenic hosts and which thus potentially serve as an important natural link among vast ranges as compared to the less-mobile intermediate hosts. In European freshwaters many calanoid and cyclopoid copepods as well as ostracods are accessible for $A$. crassus (Kirk 2003). However, the ubiquitously distributed marine copepod Eurytemora affinis has been identified as a potential key intermediate host in estuarine and brackish waters (Kirk et al. 2000b). The only currently known direct limitations to parasite dispersal are temperatures below $4{ }^{\circ} \mathrm{C}$ and lack of suitable intermediate hosts (Kirk 2003).

Driven by the continental eel trade, $A$. crassus became established as one of the most dominant parasites in the European freshwater eel due to its rapid spatial and demographic expansion (Kirk 2003; Taraschewski 2006) and only Icelandic eels are currently unaffected. Transmission takes place in fresh- and brackish water, and a vertical transfer within host families is highly unlikely (Kirk 2003) due to the European eel host's peculiar life cycle. In fact, the European coasts and rivers are the locations where the susceptible eel stages are infected after an initial $5000 \mathrm{~km}$ passive larval migration from the Sargasso Sea. Eels have long generation times, reversing their initial larval migration back to their spawning area after 10 to 20 years (Tesch 2003). This catadromous life cycle results in a nearly panmictic population with a weak but significant population genetic structure (Wirth \& Bernatchez 2001; Maes \& 
Volckaert 2002; Maes et al. 2006). Although the current decline in recruitment of European eels coincides with the arrival of the parasite, multiple factors other than diseases and parasites are implicated and include intensified fishing, barriers to both upstream and downstream migrations, pollution and changes in oceanic currents (Castonguay et al. 1994; Behrmann-Godel \& Eckmann 2003; Knights 2003; Wirth \& Bernatchez 2003; Kettle \& Haines 2006). However, evidence for virulence and fatalities in European eels are numerous and indicate potential threats due to swimbladder infestations (e.g. Gollock et al. 2005; Knopf 2006; Lefebvre et al. 2007). Of even greater concern are the results gathered from exhaustion swim tunnel experiments demonstrating that sexually mature silver eels reached lower cruising speeds and had higher costs of transport compared to healthy individuals, when swimbladders were either highly parasitized or otherwise damaged after infection (Palstra et al. 2007). If true, these fishes may fail to complete their reproductive migration back to their birthplace in the Sargasso Sea. Clearly, under such a peculiar and extreme stress situation paired with elevated susceptibility to infection (Palstra et al. 2007), the impact of a blood parasite can be lethal in migrating, nonfeeding silver eel stages (Lefebvre et al. 2007).

A previous study on $A$. crassus that relied on random amplified polymorphic DNA (RAPD) markers (Rahhou et al. 2005) suggested that populations from the Mediterranean Sea differed from those of the Atlantic and the North Sea. Moreover, the absence of a significant correlation between genetic and geographic distances supported a multiple introduction scenario for this parasite. However, this type of genetic marker has its caveats. It is sometimes lacking reproducibility (Penner et al. 1993), and owing to its nondiscriminatory characteristics, is highly sensitive to DNA contamination in this system (eel blood in the nematodes' intestines; larvae in the females' uteri). Even after careful cleaning and dissection, one cannot entirely eliminate incidental host DNA, and therefore, co-amplification during the RAPD polymerase chain reaction (PCR) might blur the real signal, or even worse, generate a wrong signature.

Here, in order to overcome these caveats, we combined the genetic information contained in seven species-specific microsatellite markers (Wielgoss et al. 2007) with sequence data derived from a fragment of the mitochondrial cytochrome $c$ oxidase subunit I (COI). The aims of this study were to (i) explore the population structure of $A$. crassus in its entire range, (ii) compare allelic and genotypic composition among Asian native and nonindigenous, invasive populations, and (iii) determine if biogeographic discontinuities appear between western Europe, northern Europe and the Mediterranean area. Understanding the epidemiology and the phylogeography of this invasive nematode will help us to reconstruct the recent spread of this alien species and its secondary genetic differentiation.

\section{Materials and methods}

\section{Sample collection}

A total of 512 adult individuals of the parasitic nematode Anguillicola crassus were collected from 15 different localities in Europe (11), at the North American East Coast (1) and in East Asia (3) between October 2003 and October 2006, with the exception of samples from the River Tiber which were sampled in 1996 (Table 1; Figs 1 and 2) and preserved in $75 \%$ ethanol. All specimens were identified as A. crassus by applying taxonomic tools (Moravec \& Taraschewski 1988), and in addition, two parasitological measures were examined (parasite prevalence and mean intensities; sensu Bush et al. 1997). We randomly chose and analyzed only one nematode per eel for all invasive populations, to avoid samples composed of siblings. In contrast, due to much lower parasite abundance in the sampled Japanese eels (Table 1), all specimens of Asian origin were genotyped. One individual Japanese eel sampled in Mikawa Bay contained an infrapopulation (sensu Bush et al. 1997) of 17 nematodes, which we considered as an additional population, MIK-2, thus increasing the number of populations to 16 .

\section{DNA extraction}

Extraction of DNA in nematodes is prone to intra- and interspecific DNA contamination (Anderson et al. 2003; Wielgoss et al. 2007). To avoid foreign DNA, tissue was exclusively derived from the apical parts of the nematode bodies and L2-larvae which are sporadically attached to the exterior were removed along with the nematode's epidermis. Total DNA was extracted (Bruford et al. 1992), additionally treated with $30 \mu \mathrm{g}$ of RNase A prior to precipitation, and resuspended in $25 \mu \mathrm{L}$ of $0.1 \times$ Tris-EDTA buffer ( $\mathrm{pH}$ 8.0). DNA yield and quality was roughly gauged on $1.0 \%$ TAE-agarose gels and compared to HindIIIrestricted $\lambda$-DNA (Pharmacia).

\section{Microsatellite analyses}

A total of 490 individuals were successfully genotyped at seven microsatellites loci as previously described (Wielgoss et al. 2007). The PCR products were diluted 1:20 in fully deionized water. For genotyping, amplicons were poolplexed in two groups: group $1(\mathrm{AcrCT} 04+29+103)$ and group 2 $($ AcrCT27 $+53+54+$ AcrCA102). Then, $1.2 \mu \mathrm{L}$ of the bulk dilution was added to a sequencing plate containing $0.2 \mu \mathrm{L}$ of ABI's standard GeneScan 500 ROX and $10.8 \mu \mathrm{L}$ of HiDiFormamide. Reactions were genotyped on a 3100 Genetic Analyzer (ABI-Hitachi) and scored in GENOTYPER version 4.0 for Windows NT, after visual inspection. Scoring of loci was reliable, and repeating a subset of individuals for each locus did not challenge the initial allele calls. 
Table 1 Sampling locations of Anguillicola crassus specimens including information on habitat characteristics, geographic position, sample sizes used for genetic analyses, year of catchment and two parasitological parameters (Bush et al. 2001), i.e. parasite prevalence (relative numbers of eels infected) and mean infection intensity (number of parasites per infected eel swimbladder)

\begin{tabular}{|c|c|c|c|c|c|c|c|c|c|c|c|}
\hline \multirow[b]{2}{*}{ \# } & \multirow[b]{2}{*}{ Ref } & \multirow[b]{2}{*}{ Site (country) } & \multirow[b]{2}{*}{$\mathrm{Hab}$} & \multicolumn{2}{|c|}{ Geographic position } & \multicolumn{2}{|c|}{ Sample sizes } & \multirow[b]{2}{*}{ Date of collection } & \multirow{2}{*}{$\begin{array}{l}\text { Prevalence } \\
(\%)\end{array}$} & \multirow{2}{*}{$\begin{array}{l}\text { Mean } \\
\text { infection } \\
\text { intensity }\end{array}$} & \multirow{2}{*}{$\begin{array}{l}\text { Sample } \\
\text { collector }\end{array}$} \\
\hline & & & & Latitude (dec) & Longitude (dec) & mtDNA & STR & & & & \\
\hline 1 & ALA & Åland Islands (FI) & $\mathrm{R}$ & $60.12 \mathrm{~N}$ & $19.90 \mathrm{E}$ & 16 & 15 & July-August 2005 & 25.5 & 3.6 & HPF \\
\hline 2 & OER & Kullen, Øresund/Kattegat (SE) & M & $56.18 \mathrm{~N}$ & $12.27 \mathrm{E}$ & 30 & 24 & October 2003 & 46.4 & 8.6 & HW; PC \\
\hline 3 & SLP & Slapton Ley (GB) & $\mathrm{R}$ & $50.24 \mathrm{~N}$ & $3.68 \mathrm{~W}$ & 15 & 15 & May-June 2005 & 53.9 & 1.8 & $\mathrm{~PB}$ \\
\hline 4 & NEA & Lake Neagh (GB) & $\mathrm{L}$ & $54.65 \mathrm{~N}$ & $6.22 \mathrm{~W}$ & 31 & 40 & May 2005 & 100 & 7.8 & $\mathrm{DE}$ \\
\hline 5 & SHA & Lough Dergh, Shannon (IE) & $\mathrm{L}$ & $52.67 \mathrm{~N}$ & $8.63 \mathrm{~W}$ & 30 & 37 & September 2005 & n.d. & n.d. & $\mathrm{KMcC}$ \\
\hline 6 & FRE & Bois Joli, Frémur (FR) & $\mathrm{L}$ & $48.56 \mathrm{~N}$ & $2.08 \mathrm{~W}$ & 31 & 39 & October 2006 & 57.1 & 6.3 & $\mathrm{SW}$; JG; JMC \\
\hline 7 & VIL & Brain-sur-Vilaine (FR) & $\mathrm{R}$ & $47.7 \mathrm{~N}$ & $1.90 \mathrm{~W}$ & 30 & 44 & June 2005 & 64.9 & 3.9 & $\mathrm{CB}$ \\
\hline 8 & LOI & Angers, Loire (FR) & $\mathrm{R}$ & $47.5 \mathrm{~N}$ & $0.57 \mathrm{~W}$ & 32 & 50 & February 2005 & 71.7 & 3.7 & TW \\
\hline 9 & ORI & Oria $(\mathrm{ES})$ & $\mathrm{R}$ & $43.27 \mathrm{~N}$ & $2.03 \mathrm{~W}$ & 30 & 17 & June-September 2005 & 25.0 & 3.7 & ED \\
\hline 10 & RHO & Camargue, Rhône (FR) & $\mathrm{R}$ & $43.50 \mathrm{~N}$ & $4.50 \mathrm{E}$ & 30 & 42 & October 2004-March 2005 & n.d. & 6.3 & $\mathrm{AC}$ \\
\hline 11 & TIB & Roma, Tiber (IT) & $\mathrm{R}$ & $41.80 \mathrm{~N}$ & $12.60 \mathrm{E}$ & 30 & 40 & 1996 & 66.3 & 5.2 & $\mathrm{EC} ; \mathrm{FB}$ \\
\hline 12 & $\mathrm{KAO}$ & Tung-chiang, Kao-Ping (TW) & $\mathrm{R}$ & $22.51 \mathrm{~N}$ & $120.42 \mathrm{E}$ & 46 & 44 & October 2006 & 60.0 & 2.8 & HT; YSH \\
\hline 13 & MIK & Mikawa Bay (JP) & M & $35.47 \mathrm{~N}$ & 137.07E & 29 & 29 & Aug 2005-February 2006 & 1.57 & 2.8 & JA \\
\hline 14 & YAM & Yamaguchi, Fushino (JP) & $\mathrm{R}$ & $34.17 \mathrm{~N}$ & $131.48 \mathrm{E}$ & 7 & 9 & October 2006 & n.d. & 2.5 & HT; HS \\
\hline 15 & STJ & St Jones River (US) & $\mathrm{R}$ & $39.07 \mathrm{~N}$ & $75.42 \mathrm{~W}$ & 32 & 45 & August 2005 & 34.0 & n.d. & $\mathrm{CC} ; \mathrm{DF}$ \\
\hline
\end{tabular}

\#, consecutive number; Ref, reference name; Hab, habitat characteristic; R, riverine; L, lacustrine; M, marine; mtDNA, mitochondrial DNA; STR, microsatellites; HPF, Hans-Peter Fagerholm; PB, Polly Bown; HW, Hakan Wickström; PC, Patrik Clevestam; DE, Derek Evans; KMcC, Kieran McCarthy; CB, Cédric Briand; ED, Estibaliz Diaz; AC, Alain Crivelli (AC); SW, Sébastien Wielgoss; JG, Jérome Guillouët; JMC, Jean-Marie Caraguel; EC, Eleonora Ciccotti; FB, Federica Berrilli; CC, Colette Cairns; DF, Dewayne Fox; JA, Jun Aoyama; HT, Horst Taraschewski; HS, Hiroshi Sato; YSH, Yu-San Han. FI, Finland; SE, Sweden; GB, Great Britain; IE, Ireland; FR, France; IT, Italy; ES, Spain; TW, Taiwan; JP, Japan; US, United States. n.d., not determined. 


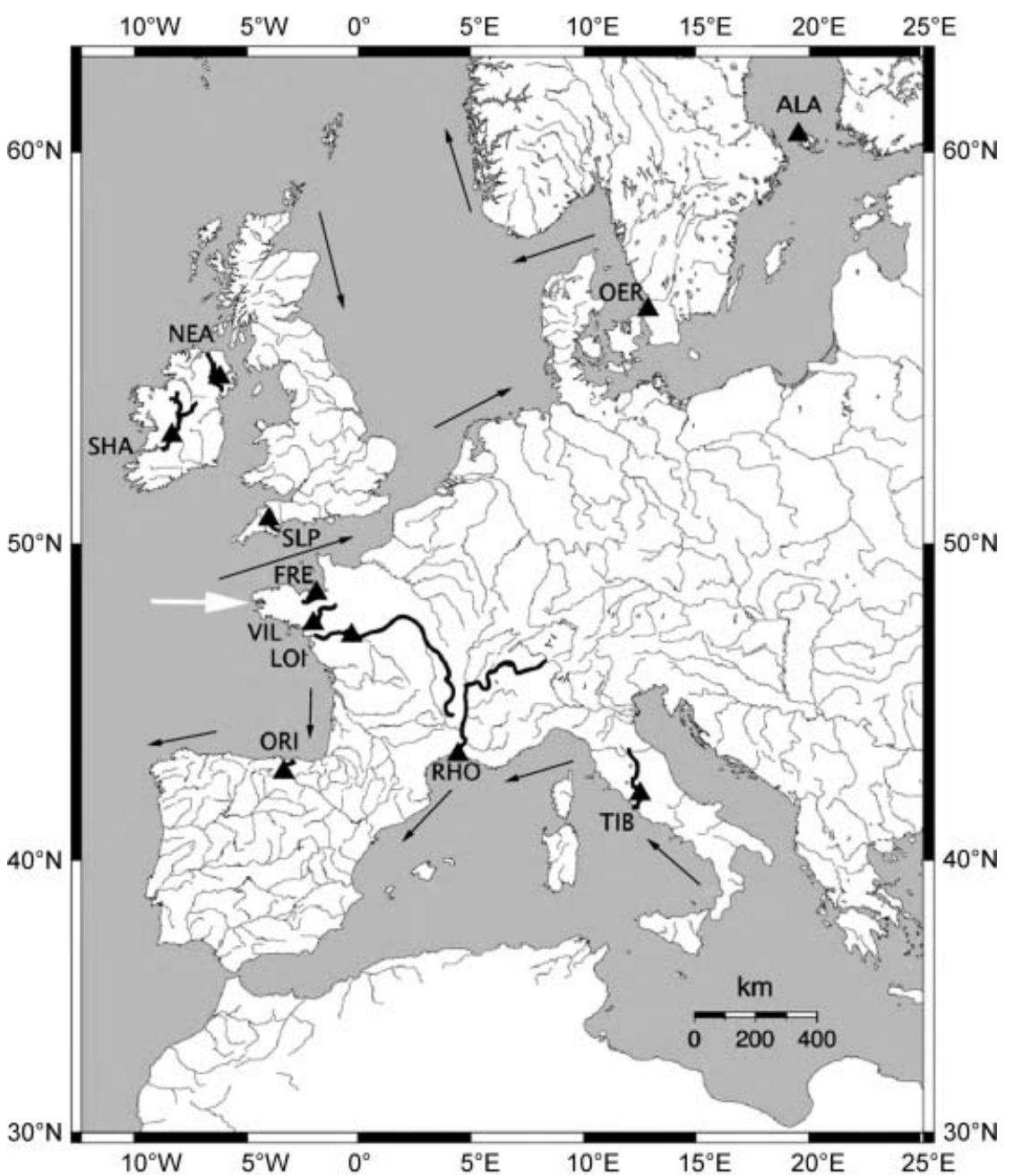

Fig. 1 Sampling locations of the swimbladder parasite Anguillicola crassus (indicated by black triangles) covering most of the distributional range of its host Anguilla anguilla in Europe. The course of each sampled river system is highlighted in thick black lines. General marine circulation patterns have been indicated by black arrows, and Briggs's (1974) major biogeographic break-point of marine benthic zones within Europe is displayed by a single white arrow pointing at Brittany. Sample sizes are as follows: ALA, Åland Islands ( $n=16)$; OER, Øresund $(n=30)$; SLP, Slapton Ley $(n=15)$; NEA, Lake Neagh $(n=40)$; SHA, River Shannon ( $n=37)$; FRE, River Frémur $(n=39)$; VIL, River Vilaine $(n=44)$; LOI, River Loire $(n=50)$; ORI, River Oria $(n=30)$; RHO, River Rhône $(n=42)$; TIB, River Tiber $(n=40)$.

\section{Mitochondrial DNA sequencing}

The mitochondrial locus cytochrome $c$ oxidase subunit I(COI) was partly sequenced (552 bp) for a total of 419 individuals. In general, a subset of 30 individuals per population was picked randomly prior to sequencing, except for populations for which fewer specimens were available, in which case all specimens were sequenced. A $25-\mu \mathrm{L}$ reaction contained $200 \mathrm{~nm}$ of each of the universal invertebrate primers HCO2198 and LCO1490 (Folmer et al. 1994), $1 \times$ of Genaxxon's Reaction Buffer S (10 mm Tris- $\mathrm{HCl}, \mathrm{pH} 8.3,50 \mathrm{~mm} \mathrm{KCl}$, $1.5 \mathrm{~mm} \mathrm{MgCl} 2,0.1 \%$ Triton X-100); $200 \mathrm{~nm}$ of each dNTP; 1 $\mathrm{U}$ of RedTaq (Genaxxon); and 10-100 ng of gDNA. An initial 3-min hot start at $94^{\circ} \mathrm{C}$ was followed by 35 cycles of denaturation for $35 \mathrm{~s}$ at $94{ }^{\circ} \mathrm{C}$, annealing for $1 \mathrm{~min}$ at $40^{\circ} \mathrm{C}$ and elongation for $1 \mathrm{~min} 30 \mathrm{~s}$ at $72{ }^{\circ} \mathrm{C}$, ending with a final elongation step of $15 \mathrm{~min}$ at $72{ }^{\circ} \mathrm{C}$. The PCR fragments were purified using silica-based spin columns (PeqLab) and directly sequenced on an ABI 3100 using BigDye terminator chemistry (Perkin Elmer). Haplotypes were deposited in GenBank (Accession nos. EU376536-EU376954).

\section{Data analysis and statistical evaluation}

Microsatellites. To circumvent the problem of undetected population structure when checking for allele-size effects on heterozygote-dependent measures, a locus-by-locus analysis of molecular variance (AMOVA) was performed using ARLEQUIN version 3.11 (Excoffier et al. 2005), which included intra-individual level variance related to $F_{\mathrm{IS}}$. Subsequent analyses using MICROCHECKER (van Oosterhout et al. 2004) revealed the presence of null alleles at two loci, and their frequency was estimated using the Brookfield estimation. Both observed and expected heterozygosities, as well as $F_{\text {IS }}$ (Weir \& Cockerham 1984) values were calculated using GENETIX version 4.05 (Dawson \& Belkhir 2001). Deviations from both Hardy-Weinberg equilibrium (HWE) for single loci, and linkage disequilibrium (LD) among pairs of loci were determined using Fisher's exact tests in GENEPOP version 3.4 (Raymond \& Rousset 1995). Markov chain analyses were applied to estimate significance (10 000 dememorization steps, 1000 batches and 10000 iterations per batch), and corrected for combined type I errors using 


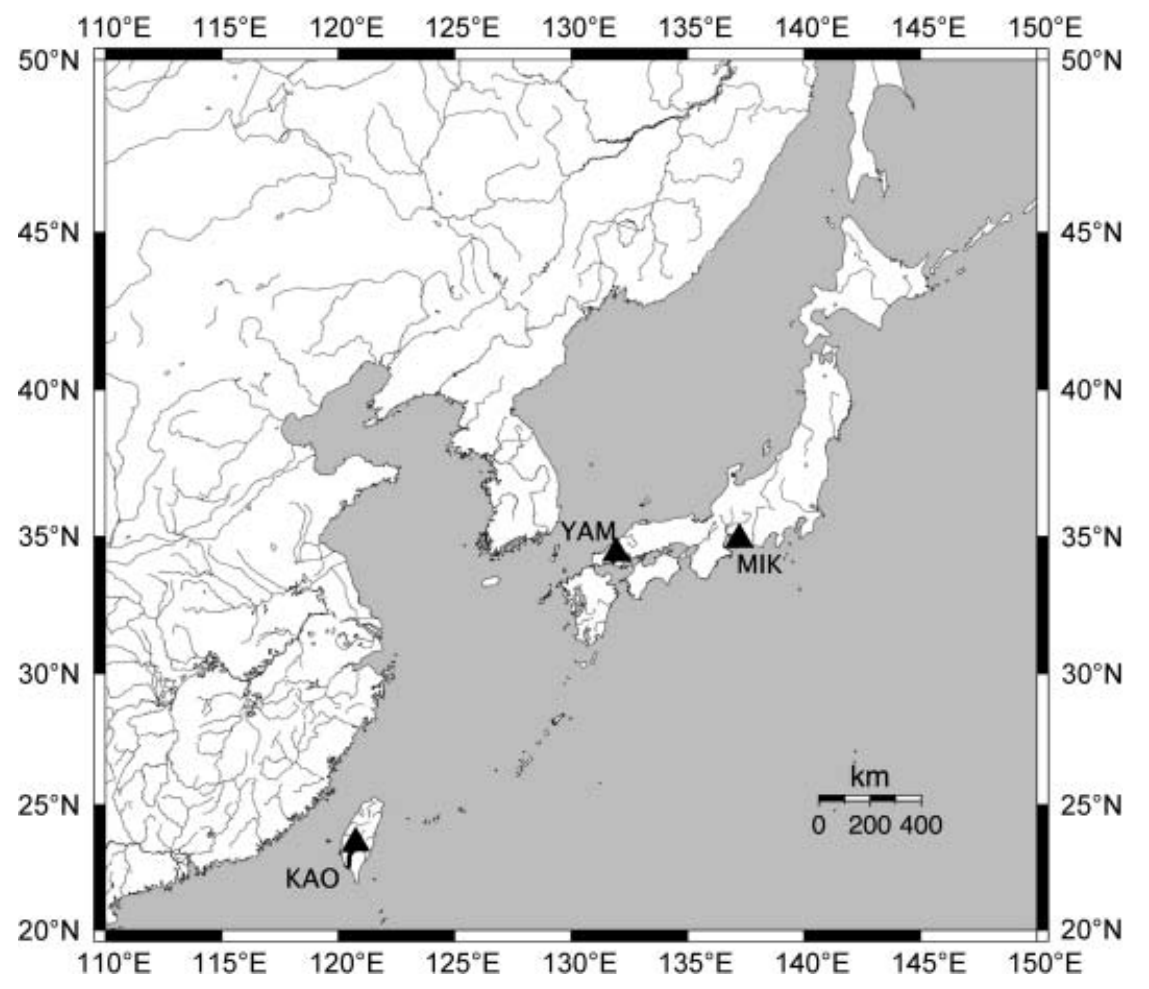

Fig. 2 Sampling locations of Anguillicola crassus from native habitats in Southeast Asia. Sample sizes are as follows: $\mathrm{KAO}$, River Kao-Ping, Taiwan $(n=46)$; MIK, Mikawa Bay, Japan $(n=29)$; YAM, River Fushino, Prefecture of Yamaguchi, Japan $(n=9)$. sequential Bonferroni tests (Sokal \& Rohlf 1995). Locus-wise total and private allelic counts were conducted using HPRARE (Kalinowski 2005). The calculations were performed for $n=24$ genes per sample. Pairwise $\theta_{\mathrm{ST}}$ estimates (Weir \& Cockerham 1984) between pairs of populations were calculated and evaluated for deviations from the null hypothesis of panmixia after 10000 permutation steps in ARLEQUIN version 3.11 (Excoffier et al. 2005). In addition, genetic differentiation for both $F_{\mathrm{ST}}$ and $\rho_{\mathrm{ST}}$, an unbiased version of $R_{\mathrm{ST}}$, based on the stepwise mutation model (Slatkin 1995; Rousset 1996), were calculated in GENEPOP version 3.4 (Raymond \& Rousset 1995) and compared to absolute and straight line geographic distances, which were derived from longitudinal and latitudinal positions (Table 1). Significance of the correlation was assessed applying a Mantel test (Mantel 1967) implemented in PASSAGE version 2 (Rosenberg 2008). In order to exclude possible effects of nonstandardized values on the outcome of the Mantel tests, we also considered a standardized measure of $F_{\mathrm{ST}}$. The standardization was performed as suggested by Meirmans (2006) and indexed as $\theta_{\mathrm{ST}}^{\prime}$. Based on the sampling coordinates in Europe (Table 1), we further assessed phylogeographic patterns by testing for the presence of genetic barriers using Monmonier's (1973) algorithm of maximum differences implemented in the program BARRIERs version 2.2 (Manni et al. 2004). The nematode population structure was inferred based on a Bayesian clustering approach implemented in STRUCTURE version 2.2 (Pritchard et al. 2000; Falush et al.
$2003,2007)$. We chose the admixture model, which best fits the nematode's purely sexual mode of reproduction and no prior information about the population geographic origin was used. To assess the most likely number of populations $(K)$, we ran several tests varying the number of populations for $K=1-10$. The data set was iterated 10 times for 200000 Markov chain Monte Carlo (MCMC) repeats and a burn-in period of 100000 steps to assess both the arithmetic means of the likelihoods and standard deviations at different $K$ values. A final run of 1 million MCMC repeat chain was conducted after a burn-in length of 100000 steps. The number of contributing populations was statistically tested using two different approaches. First, the ad-hoc statistic $\Delta K$ proposed by Evanno et al. (2005) was applied. This procedure is sensitive to pronounced changes in mean log-likelihood values between successive Ks and the degree of variance of any given mean. Second, the related point estimate $\mathrm{E}$ $(K \mid X)$ for actual number of $K$ populations contributing to the structure within the data set was inferred using STRUCTURAMA version 1.0 (http://www.structurama.org), which implements the Gibbs and split-merge sampler described by Pella \& Masuda (2006). This program allows for an independent estimation of the Dirichlet parameter $\alpha$ (Huelsenbeck \& Andolfatto 2007). The settings were as follows: five chains were run in parallel and samples were taken every 10th step from $300000 \mathrm{MCMC}$ repeats, resulting in a total data set of 30000 steps. Both the number of assumed populations $K$ and the Dirichlet parameter $\alpha$ were 
estimated independently without priors (the shape parameter of the $\gamma$-distribution was fixed at $\alpha=1$ ). Burn-ins of 100 , 1000 , and 10000 steps were applied. The graphic display of the STRUCTURE results was generated using DISTRUCT (Rosenberg 2004). Cavalli-Sforza \& Edwards' (1967) chord distance was used to construct a phylogenetic tree using a neighbour-joining algorithm (Saitou \& Nei 1987) implemented in POPULATIONS version 1.2.30b (http:// bioinformatics.org). Support for the tree nodes was assessed by bootstrapping over individuals (100 iterations). A factorial component analysis (FCA) implemented in GENETIX version 4.05 (Dawson \& Belkhir 2001) extracted a set of orthogonal axes of variation ranked by informativeness. The threedimensional scatter plot based on the output matrix of eigenvalues was recalculated in STATISTICA version 6.0.

Mitochondrial DNA. Haplotypic diversity $h$ (Nei \& Tajima 1981), nucleotide diversity $\pi$ (Nei 1987), Fu's Fs (Fu 1997) and population genetics estimators (Weir \& Cockerham 1984) were calculated in ARLEQUIN version 3.11 (Excoffier et al. 2005). An AMova was also performed (Excoffier et al. 1992) to compare geographic partitioning based on haplotype frequencies. A minimum-spanning haplotype network was constructed using the TCs version 1.20 software (Clement et al. 2000). This network was compared to a maximumlikelihood tree to correct for ambiguous, multiple connections. All redundant sequences were removed from the data set using COLLAPSE version 1.2 (http://darwin.uvigo.es) and the best-fit model of sequence evolution $(\mathrm{HKY}+\mathrm{G}+\mathrm{I})$ was determined using MODELTEST version 3.4 (Posada \& Crandall 1998), which estimated the shape parameter of the $\gamma$-distribution, $\alpha=0.8848$, and the proportion of invariable sites, $\mathrm{P}_{\text {invar }}=0.6788$. Finally, a phylogenetic tree based on maximum-likelihood criteria under the given model was inferred in PAUP* version $4.0 \mathrm{~b} 10$ (Swofford 2003) and compared to the haplotype network derived by the parsimony approach in TCs.

\section{Results}

\section{Microsatellites}

Intrapopulation diversity, Hardy-Weinberg and linkage equilibrium, and the neutrality of loci. All microsatellite loci examined were highly variable ranging from 15 (AcrCA102) to 65 (AcrCT04) alleles per locus ( $n=490$; Table S1, Supplementary material). Exact tests for linkage disequilibrium (LD) only showed two instances of linked loci $(\alpha<0.0002)$, restricted to the MIK-2 infrapopulation, i.e. AcrCT04-AcrCT103 and AcrCT04-AcrCT53, respectively. Native Asian populations were genetically more diverse than recently established invasive colonies. Expected heterozygosities $\left(H_{\mathrm{E}} ;\right.$ Nei 1978) are summarized in Table S2, Supplementary material. Averaged across loci, $H_{\mathrm{E}}$ were always lower in European samples (0.755-0.874) when compared to native populations like KAO (0.906) or MIK-1 (0.907), although Baltic samples display marginally higher values than KAO in three instances. Averaged values for observed heterozygosities $\left(H_{\mathrm{O}}\right)$ were consistently lower than expected values in all locations, and the Taiwanese sample showed the highest overall value of 0.834 . Using a locus-by-locus AMOvA including intra-individual level variance three loci displayed low but significant inbreeding coefficients, AcrCT04 $\left(F_{\mathrm{IS}}=\right.$ 0.054; $P<0.001), \operatorname{AcrCT27}\left(F_{\mathrm{IS}}=0.046 ; P=0.001\right)$, AcrCT54 $\left(F_{\mathrm{IS}}=0.018 ; \quad P=0.05\right)$, whereas AcrCT29 $\quad\left(F_{\mathrm{IS}}=0.327\right.$; $P<0.001), A c r C T 53\left(F_{\mathrm{IS}}=0.229 ; P<0.001\right)$ and AcrCA102 $\left(F_{\mathrm{IS}}=0.195 ; P<0.001\right)$ showed high and significant values, with AcrCT103 (0.123; $P<0.001)$ being intermediate. Such an uneven pattern cannot be explained by population-level effects and is expected to be either due to technical or locusspecific effects. After excluding technical problems due to the reliability upon re-amplification trials of already scored individuals, we scrutinized the presence of allele size effects using the MICRO-CHECKER software (van Oosterhout et al. 2004). Whereas allelic drop-out could be excluded for any locus and population (112 comparisons), the software revealed a significant population-wide presence of null alleles at loci AcrCT53 (9 populations) and AcrCT29 (11 populations), with average null allele frequencies of $f_{\mathrm{NULL}, 53}=0.09$ and $f_{\mathrm{NULL}, 29}=0.10$, respectively. All remaining loci showed sporadic nulls with no observable trend. Although it is reasonable to assume that the bias introduced by each marker will be different, the presence of unobserved (recessive) alleles can influence the reliability of the data and may lead to overestimation of differentiation (Chapuis \& Estoup 2007). Thus, it is important to consider their influence carefully. We repeated all analyses by (i) allowing for (unobserved) null alleles, if possible, and (ii) testing fractions of markers separately by deleting either the lowest or the highest $F_{\text {IS }}$ value markers. Despite the presence of null alleles at some microsatellite loci, our results suggest that the amount of information gathered by the sum of markers outperformed the single-marker defects.

Genetic differentiation and relationships among populations. Unstandardized differentiation indices indicate a weak but significant global population structure for European populations. The global $\theta_{\mathrm{ST}}(0.057 ; 95 \% \mathrm{CI} \pm 0.0090)$ and $\rho_{\mathrm{ST}}$ $(0.059 ; 95 \% \mathrm{CI} \pm 0.012)$ are almost identical. Correction for null alleles using FREENA (Chapuis \& Estoup 2007) only marginally decreased absolute values, which indicates that null alleles were not strongly affecting the differentiation indices (Table 3). However, standardization had a large effect on the average $\theta_{\mathrm{ST}}$ value as it is increased significantly to $0.32(95 \% \mathrm{CI} \pm 0.040)$ in both uncorrected and null-corrected data sets, identical to the average $\theta_{\mathrm{ST}}$ of $0.32(95 \% \mathrm{CI} \pm 0.044)$ among European populations based on the mitochondrial DNA marker. This is a convincing value as it makes both 
Table 2 Pairwise $\theta_{\mathrm{ST}}$ values for all sampling locations (above diagonal mitochondrial COI locus; below diagonal seven microsatellite markers combined)

\begin{tabular}{|c|c|c|c|c|c|c|c|c|c|c|c|c|c|c|c|c|}
\hline \multirow{2}{*}{$\begin{array}{l}\text { Regions } \\
\operatorname{Ref}(\mathrm{S} ; \mathrm{M})\end{array}$} & \multicolumn{4}{|c|}{ Southwest } & \multicolumn{2}{|c|}{ Brittany } & \multicolumn{5}{|c|}{ Northeast } & \multirow{2}{*}{$\frac{\text { Taiwan }}{\mathrm{KAO}}$} & \multicolumn{3}{|l|}{ Japan } & \multirow{2}{*}{$\begin{array}{l}\text { USA } \\
\text { STJ }\end{array}$} \\
\hline & RHO & TIB & ORI & LOI & VIL & FRE & SHA & NEA & SLP & OER & ALA & & Mik-1 & Mik-2 & YAM & \\
\hline RHO $(42 ; 32)$ & & $0.097^{* *}$ & $0.094^{* *}$ & $0.074^{* *}$ & $0.483^{*}$ & $0.607^{*}$ & $0.437^{*}$ & $0.517^{*}$ & $0.711^{*}$ & $0.478^{*}$ & $0.620^{*}$ & $0.496^{*}$ & $0.496^{*}$ & $0.648^{*}$ & $0.584^{*}$ & $0.741^{*}$ \\
\hline TIB $(40 ; 30)$ & $0.036^{*}$ & & -0.016 & -0.019 & $0.256^{*}$ & $0.444^{*}$ & $0.206^{*}$ & $0.284^{*}$ & $0.453^{*}$ & $0.256^{*}$ & $0.278^{*}$ & $0.227^{*}$ & $0.378^{*}$ & $0.437^{*}$ & $0.364^{*}$ & $0.536^{*}$ \\
\hline ORI $(17 ; 30)$ & $0.042^{*}$ & $0.023^{*}$ & & 0.008 & $0.253^{*}$ & $0.453^{*}$ & $0.225^{*}$ & $0.305^{*}$ & $0.461^{*}$ & $0.256^{*}$ & $0.299^{*}$ & $0.248^{*}$ & $0.377^{*}$ & $0.446^{*}$ & $0.371^{*}$ & $0.536^{*}$ \\
\hline LOI $(50 ; 32)$ & $0.025^{*}$ & $0.016^{*}$ & $0.016^{* *}$ & & $0.289^{*}$ & $0.454^{*}$ & $0.227^{*}$ & $0.304^{*}$ & $0.462^{*}$ & $0.289^{*}$ & $0.305^{*}$ & $0.256^{*}$ & $0.392^{*}$ & $0.435^{*}$ & $0.375^{*}$ & $0.537^{*}$ \\
\hline VIL $(44 ; 30)$ & $0.116^{*}$ & $0.041^{*}$ & $0.049^{*}$ & $0.053^{*}$ & & $0.144^{*}$ & $0.104^{*}$ & $0.065^{* *}$ & $0.300^{*}$ & $0.107^{*}$ & $0.080^{* *}$ & $0.093^{*}$ & $0.294^{*}$ & $0.324^{*}$ & $0.173^{* *}$ & $0.388^{*}$ \\
\hline FRE $(39 ; 31)$ & $0.169^{*}$ & $0.103^{*}$ & $0.087^{*}$ & $0.114^{*}$ & $0.042^{*}$ & & $0.287^{*}$ & $0.218^{*}$ & $0.465^{*}$ & $0.345^{*}$ & $0.347^{*}$ & $0.364^{*}$ & $0.373^{*}$ & $0.460^{*}$ & $0.218^{* *}$ & $0.550^{*}$ \\
\hline SHA $(37 ; 30)$ & $0.080^{*}$ & $0.025^{*}$ & $0.043^{*}$ & $0.041^{*}$ & $0.042^{*}$ & $0.100^{*}$ & & 0.000 & $0.318^{*}$ & $0.155^{*}$ & $0.096^{*}$ & $0.098^{*}$ & $0.325^{*}$ & $0.338^{*}$ & $0.237^{*}$ & $0.423^{*}$ \\
\hline NEA $(40 ; 31)$ & $0.092^{*}$ & $0.036^{*}$ & $0.061^{*}$ & $0.049^{*}$ & $0.040^{*}$ & $0.089^{*}$ & $0.015^{*}$ & & $0.292^{*}$ & $0.142^{*}$ & $0.069^{* *}$ & $0.093^{*}$ & $0.329^{*}$ & $0.327^{*}$ & $0.217^{*}$ & $0.406^{*}$ \\
\hline $\operatorname{SLP}(15 ; 15)$ & $0.135^{*}$ & $0.083^{*}$ & $0.087^{*}$ & $0.099^{*}$ & $0.084^{*}$ & $0.097^{*}$ & $0.067^{*}$ & $0.051^{*}$ & & $0.235^{*}$ & $0.382^{*}$ & $0.320^{*}$ & $0.346^{*}$ & $0.523^{*}$ & $0.422^{*}$ & $0.644^{*}$ \\
\hline OER $(24 ; 30)$ & $0.092^{*}$ & $0.034^{*}$ & $0.034^{*}$ & $0.045^{*}$ & $0.038^{*}$ & $0.077^{*}$ & $0.038^{*}$ & $0.040^{*}$ & $0.066^{*}$ & & 0.055 & $0.094^{*}$ & $0.303^{*}$ & $0.326^{*}$ & $0.264^{*}$ & $0.377^{*}$ \\
\hline ALA $(15 ; 16)$ & $0.097^{*}$ & $0.039^{*}$ & $0.037^{*}$ & $0.058^{*}$ & $0.038^{*}$ & $0.068^{*}$ & $0.040^{*}$ & $0.038^{*}$ & $0.056^{*}$ & 0.001 & & -0.011 & $0.293^{*}$ & $0.384^{*}$ & $0.294^{*}$ & $0.496^{*}$ \\
\hline $\mathrm{KAO}(44 ; 46)$ & $0.083^{*}$ & $0.038^{*}$ & $0.042^{*}$ & $0.044^{*}$ & $0.035^{*}$ & $0.060^{*}$ & $0.035^{*}$ & $0.035^{*}$ & $0.056^{*}$ & $0.030^{*}$ & $0.020^{*}$ & & $0.386^{*}$ & $0.358^{*}$ & $0.307^{*}$ & $0.414^{*}$ \\
\hline MIK-1 $(12 ; 12)$ & $0.090^{*}$ & $0.037^{*}$ & $0.038^{*}$ & $0.047^{*}$ & $0.042^{*}$ & $0.056^{*}$ & $0.029^{*}$ & $0.026^{*}$ & $0.045^{*}$ & $0.022^{* *}$ & $0.023^{*}$ & $0.017^{*}$ & & $0.312^{*}$ & 0.125 & $0.486^{*}$ \\
\hline MIK-2 $(17 ; 17)$ & $0.210^{*}$ & $0.161^{*}$ & $0.150^{*}$ & $0.163^{*}$ & $0.160^{*}$ & $0.173^{*}$ & $0.163^{*}$ & $0.176^{*}$ & $0.199 *$ & $0.146^{*}$ & $0.139^{*}$ & $0.120^{*}$ & $0.146^{*}$ & & $0.367^{*}$ & 0.025 \\
\hline YAM $(09 ; 07)$ & $0.202^{*}$ & $0.148^{*}$ & $0.126^{*}$ & $0.147^{*}$ & $0.134^{*}$ & $0.121^{*}$ & $0.130^{*}$ & $0.132^{*}$ & $0.170^{*}$ & $0.112^{*}$ & $0.114^{*}$ & $0.084^{*}$ & $0.123^{*}$ & $0.156^{*}$ & & $0.557^{*}$ \\
\hline STJ $(32 ; 32)$ & $0.165^{*}$ & $0.079^{*}$ & $0.110^{*}$ & $0.118^{*}$ & $0.090^{*}$ & $0.115^{*}$ & $0.090^{*}$ & $0.097^{*}$ & $0.105^{*}$ & $0.082^{*}$ & $0.069^{*}$ & $0.069^{*}$ & $0.088^{*}$ & $0.174^{*}$ & $0.129 *$ & \\
\hline
\end{tabular}

${ }^{* *} P<0.05 ;{ }^{*} P<0.01$ significantly different (10 000 permutations); bold values were not significant after Bonferroni correction $(P<0.0004) ;$ Ref, reference name; $\mathrm{S}, \mathrm{STR}$ markers; $\mathrm{M}$, mitochondrial marker. 
Table 3 Summary of global indices of differentiation and correlations between genetic differentiation were performed according to Mantel (1967) using straight geographic distance among European sampling localities

\begin{tabular}{llll}
\hline Differentiation index & Global value & $r$ & $P$ \\
\hline$\theta_{\mathrm{ST}}$ & $0.057^{*}$ & -0.100 & 0.67 \\
$\theta_{\mathrm{ST}}^{\prime}$ & $0.320^{*}$ & -0.052 & 0.80 \\
$\theta_{\mathrm{ST} \text { (ENA) }}$ & $0.056^{*}$ & -0.083 & 0.70 \\
$\theta_{\mathrm{ST} \text { (ENA) }}^{\prime}$ & $0.320^{*}$ & -0.084 & 0.51 \\
$\rho_{\mathrm{ST}}$ & $0.059^{*}$ & $\mathbf{0 . 3 9}$ & $\mathbf{0 . 0 2 8}$ \\
$\rho_{\mathrm{ST}(\mathrm{ENA})}$ & $0.053^{*}$ & $\mathbf{0 . 4 1}$ & $\mathbf{0 . 0 1 2}$ \\
\hline
\end{tabular}

Genetic differentiation indeces are defined as follows: $\theta_{\mathrm{ST}}$ and $\rho_{\mathrm{ST}}$, raw data; $\theta_{\mathrm{ST}}^{\prime}$, standardized data; $\theta_{\mathrm{ST} \text { (ENA) }}$ and $\rho_{\mathrm{ST} \text { (ENA)' }}$ null-allele-corrected data; $\theta_{\mathrm{ST} \text { (ENA) }}^{\prime}$ both standardized and null-allele-corrected data. Asterisks indicate genetic differentiation significantly different from zero. Bold values represent significant Mantel tests with $P<0.05$.

measures comparable to one another. Pairwise comparisons of $\theta_{\mathrm{ST}}$ and $\rho_{\mathrm{ST}}$ assessed among all populations behaved in parallel to overall differentiation (only pairwise $\theta_{\mathrm{ST}}$ shown). In brief, the northern localities with the Irish (SHA-NEA), and the Baltic samples (OER-ALA) were least differentiated from one another. Similarly, the southwestern populations appeared least differentiated based on pairwise indexes. Bonferroni corrections performed on $\theta_{\mathrm{ST}}$ values mainly indicated insignificant pairwise differences between southern populations and the Loire River (LOI). Most notably, among all Asian indigenous nematodes, Japanese MIK-1 and the Taiwanese sample are least differentiated from one another, despite their geographic distance. In fact, these localities share a similar level of differentiation to either of the invasive populations in Europe. Among Asian localities, YAM and MIK-2 are dissimilar to the MIK-1 and KAO samples and are both highly differentiated from European locations. Finally, the St Jones River population from North America is least differentiated from KAO and the northeastern European population of ALA.

Population structure and genetic admixture analysis. Given our microsatellite data for 16 populations, the estimated likelihood measures $\ln P(D)$ for the number of assumed populations $(K)$ increased from $K=1$ to $K=6$, at which point the curve reaches a plateau (Fig. S1a, Supplementary material). When accounting for null alleles (Falush et al. 2007), the same pattern became apparent (Fig. S1c). A sensitivity analysis which excluded either non-HWE or HWE markers confirmed the stability of the overall pattern, in which we inferred a minimum value of $K=2$, separating the southwestern populations from the remainder of the sampling locations (Fig. S2a-h, Supplementary material). This is supported using Evanno et al.'s (2005) ad hoc statistic
$\Delta K$. The two highest rankings were obtained for $K=2$ and $K=4$, respectively, both times with and without correction for null alleles, Fig. S1b and d). However, a scenario with $K=4$ might best explain the data (Fig. 3) which is substantiated by both the shape of the likelihood saturation curves (Fig. S1a and c), and the Dirichlet process in STRUCTURAMA (Huelsenbeck \& Andolfatto 2007) that estimated the most probable number of populations $\mathrm{E}$ $(K \mid X)=4.03$; with $\operatorname{Var}(K \mid X)=0.725\left(\alpha_{\text {ESTIMATE }}=0.591\right.$; $\operatorname{Var}$ $(\alpha \mid X)=0.106)$. Since structurama did not allow for the corrections of null alleles, caution must be taken here. While the burn-in length variation between 100 and 10000 steps had no measurable effect, sensitivity analysis revealed a lower number of $K$ for the low- $F_{\text {IS }}$-marker-set $(K=2.70)$ compared to the complementary set $(K=5.02)$. This slight overestimation is expected, when null alleles are present (Chapuis \& Estoup 2007). In sum, two major population signatures are apparent in Europe: a northeastern cluster (ALA, OER, SLP, NEA, SHA), and a southwestern group (LOI, ORI, RHO, TIB), while under the four-population scenario, an additional northwestern French population is proposed with Brittany (FRE, VIL). Interestingly, this region is located at an intermediate geographic position relative to the other two groupings. Surprisingly, only the northeastern European (towards both KAO and MIK-1) and the North American sample (towards both YAM and MIK-2) show affinities to Asian populations under the four-population scenario. However, one has to bear in mind that native populations have not been sampled exhaustively and that the data presented here may not conform to the model assumptions in an ideal manner, since HWE and linkage equilibrium might not have been reached in the introduced populations within such a short time span.

Both the southwestern and the northeastern European locations indicate a considerable amount of gene flow in either direction; with several individuals being completely displaced according to their proposed population origins. The northeastern European population signature resembles the Taiwanese one, whereas only weak Taiwanese signatures can be detected in Brittany and the southwestern European samples. One part of the sample collected in Japan (MIK-1) cannot be distinguished from the Taiwanese population, whereas the MIK-2 infrapopulation derived from one single eel swimbladder, shares a completely different signature with samples from the Japanese River Fushino (YAM) and the North American St Jones River (STJ). From such a pattern it is clear, that even among Asian nematode populations there will be considerable amount of gene flow despite significant distances among regions. To test for the influence of MIK-2 (putative sibship) and YAM (smallest sampling size) on our results we excluded them both. All previously detected groupings remained stable and the North American sample is always separated from the remainder of the data set at $K=4$ (data not shown). 


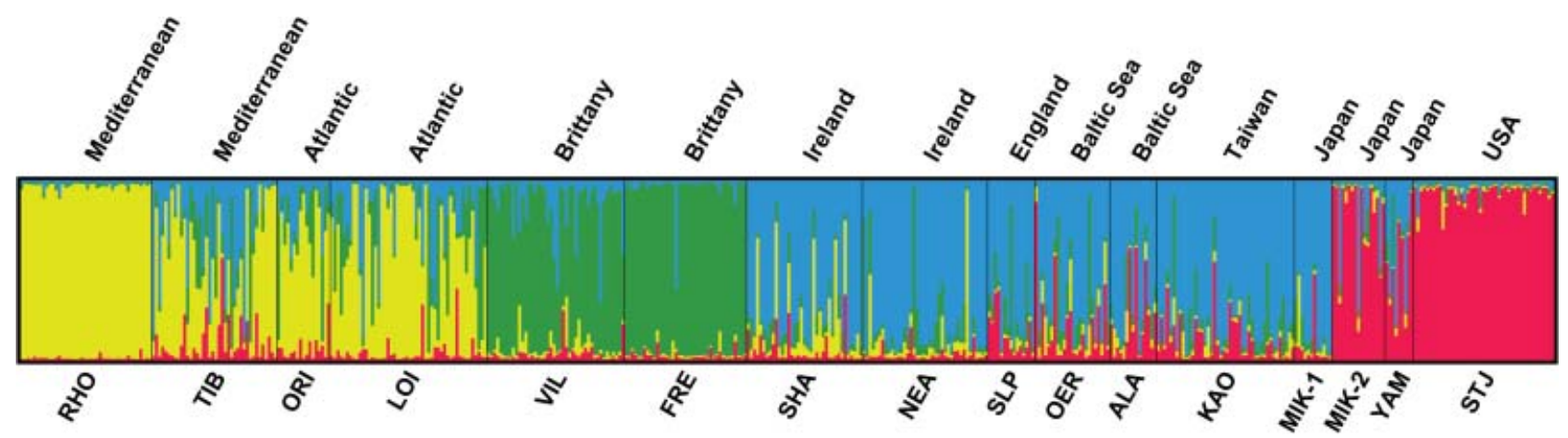

Fig. 3 Individual-based cluster representation based on Bayesian inference of population structure $[K=4 ; \ln P(D)=-16732.8$; burn-in period = 100 000; MCMC repeat length = 1000 000; Pritchard et al. 2000]. Each colour represents one assumed population cluster K. Multiple coloured bars display an individual's estimated membership proportion in more than one population (q), i.e. admixture. Sampling locations are ordered from southern to northeastern Europe from left to right, followed by Asian and North American samples. The labels indicate sampling location (below; for abbreviations refer to Table 1) and the region of origin (above).

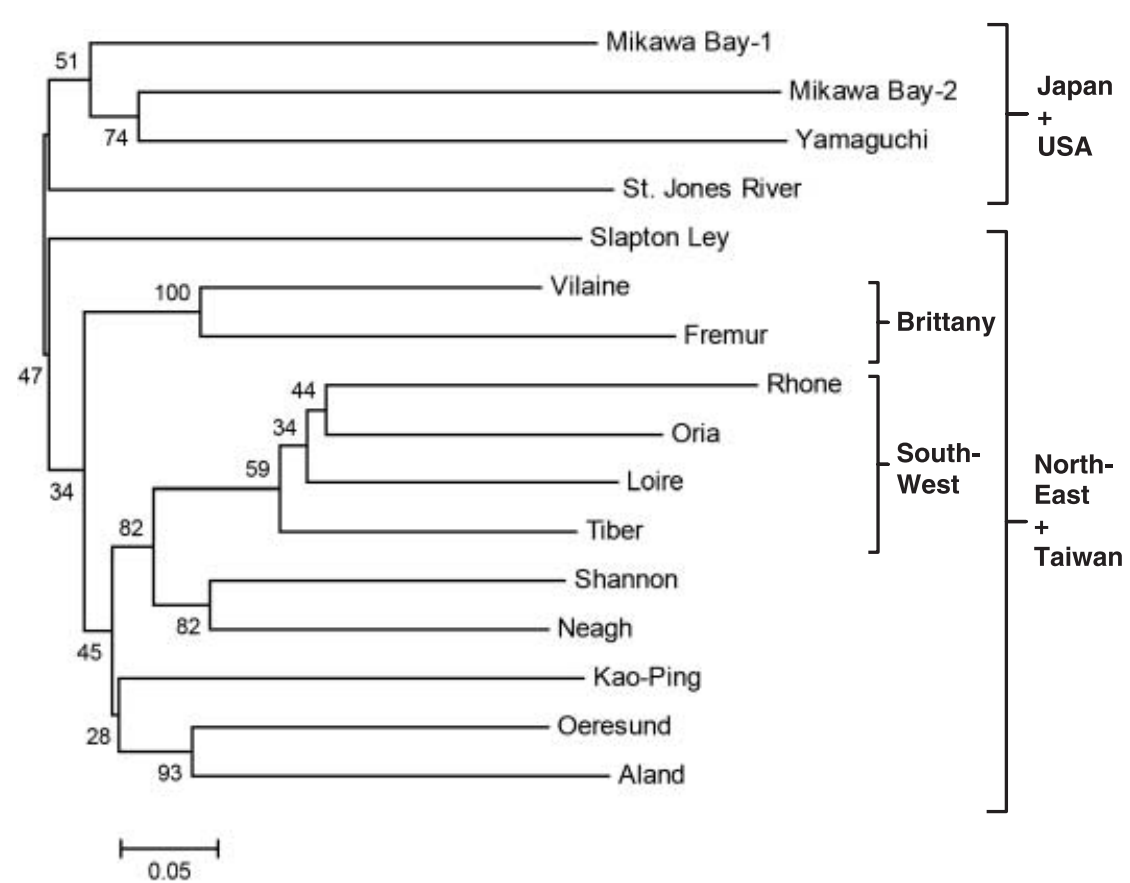

Fig. 4 Neighbour-joining (NJ) phenogram summarizing Cavalli-Sforza \& Edwards's (1967) $D_{\mathrm{CE}}$ chord distances corrected for null-alleles (Chapuis \& Estoup 2007) among 12 invasive and four native populations. European groupings are highlighted by brackets based on the STRUCTURE tool. The outgroup was defined according to the tree's midpoint. Values on the nodes represent the percentage of bootstrap replicates over loci $(n=100)$. Branch lengths are proportional to the genetic distance between the taxa. The scale bar represents a distance $D_{\mathrm{CE}}$ of 0.05 .
While no prior information was used in the Bayesian clustering approach, the midpoint-rooted neighbour-joining tree incorporated the geographic origin of individuals. Chapuis \& Estoup (2007) suggested that correction for null-alleles is reliable for $D_{\mathrm{CE}}$ distances. Upon correction of the data set for the presence of null alleles, the topology of the tree slightly changed (Fig. 4), by placing MIK-1 into the Japanese-US clade compared to the uncorrected phenogram (Fig. S4, Supplementary material). In essence, it can be inferred that the North American (STJ) and the Japanese populations markedly differed from the remaining data set, conforming to the findings using STRUCTURE and pairwise indices of differentiation. Moreover, there is strong statistical bootstrap support for biogeographically relevant clades such as Brittany (VIL, FRE), Ireland (SHA, NEA), the Baltic Sea (OER, ALA) and the southwestern (LOI, ORI, RHO, TIB) populations. The weak support of deep splits reflects the very recent expansion of the nematode in Europe and shared ancestry with the Taiwanese population, which is best reflected in Fig. 4. Moreover, whereas the Brittany and southwestern samples are both monophyletic groups, they both cluster within the northeastern samples, suggesting a common invasion history of all European samples.

FCA and AMOVA. Based on the microsatellite genotypes, we conducted an FCA. Three individual genotypes, all from 
Japanese MIK-1 (MIK08, 29 and 30) contained most of the variability found in the data set, which rendered the remaining data set uninformative. After removal of these outliers, the first three axes represented $4.6 \%$ of the total variance. The southwestern European samples separate from the northeastern ones along the first axis, while most of the Brittany samples are distinguishable from the remaining individuals along the second axis (Fig. S3, Supplementary material). The Japanese samples are separated along the third axis. Interestingly, the Taiwanese population clustered approximately within the northeastern European 'data cloud' central to all other clusters, whereas about two-thirds of the Japanese samples scatter yet in a different area of the factorial space. The analysis does not consider null alleles, however, a sensitivity analysis excluding either null allele suspect or nonsuspect markers yielded comparable results, respectively (data not shown). When populations were grouped to demes according to STRUCTURE and FCA analyses (northeastern, Brittany, southwest), an analysis of molecular variance revealed that most of the genetic variance was confined within the populations (92.84\%). The remaining molecular variance was found among groups $(3.98 \%)$ and among populations within groups (3.18\%); $\Phi_{\mathrm{ST}}=0.0716 ; \Phi \mathrm{SC}=0.0331 ; \Phi_{\mathrm{CT}}=0.0398$.

Allelic richness and private alleles. After rarefaction, the number of alleles per locus was higher in the native Taiwanese (KAO) and Japanese (MIK-1) populations when compared to the European and North American populations (Table S1), with the exception of locus AcrCT103 in MIK-1. The MIK-2 infrapopulation, collected from only one swimbladder, and the modestly sized YAM sample $(N=9)$ exhibited low numbers of alleles per locus, which likely is a result of lumping the closely related individuals from single swimbladders. This result surely does not reflect the real genetic divergence of the parasite in these areas, as suggested by the aforementioned MIK- 1 and KAO samples. We also calculated the allelic richness for the different clusters detected within Europe with the STRUCTURE algorithm. While single-population data are less informative (Fig. S5, Supplementary material), an apparent cline can be observed when locations are grouped according the fourpopulation scenario (Fig. 5a). The highest allelic richness is, as expected, found in East Asia, followed by the north European, Brittany and finally the most depauperate southwestern European samples. The number of alleles per locus among European geographic groups was not significantly different at the $5 \%$ level (two-tailed $t$-tests and unequal variance between groups). Only the northeast vs. southwest comparison was almost significant $(P=0.077)$. However, differences between the average values for Taiwanese and southwestern European, as well as the Taiwanese and the Brittany samples, respectively, were significant according to the two-tailed $t$-tests $(0.0117$ and
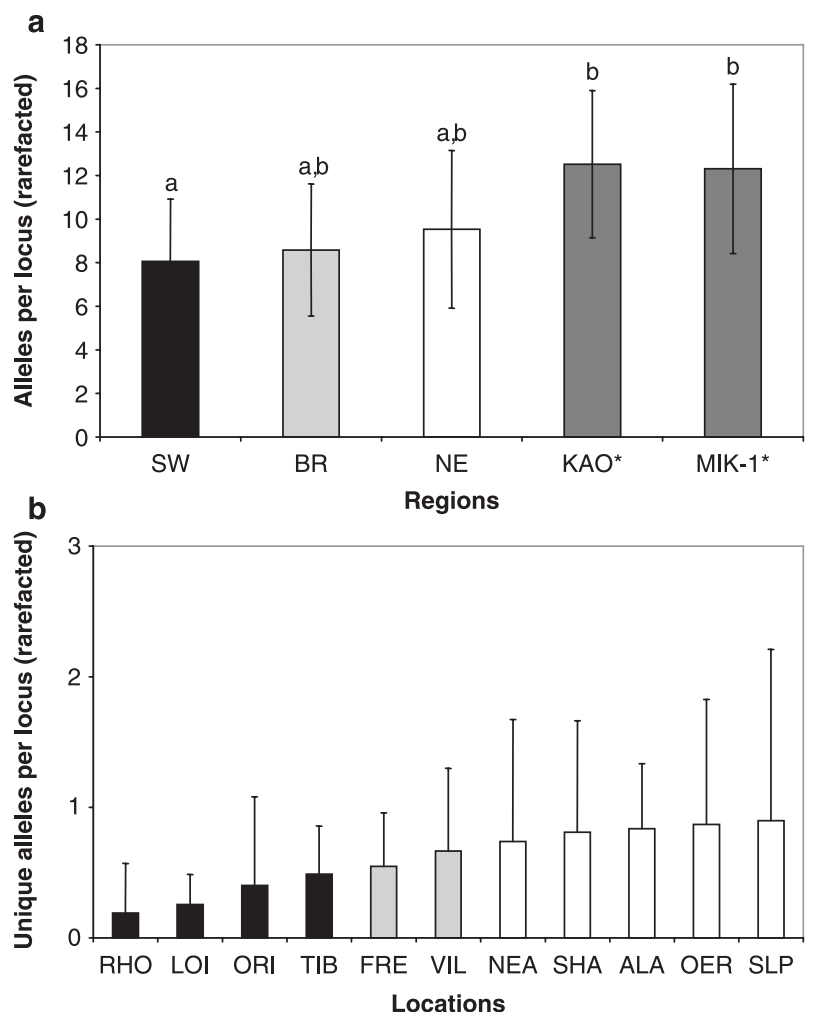

Fig. 5 Box plot representation of (a) mean allelic richness (rarefacted number of alleles per locus) between invasive European and native Asian $\left(^{*}\right)$ regions; SW (black), southwestern European locations; BR (grey), Brittany locations; NE (white), northeastern European locations; KAO, Kao-Ping, Taiwan (dotted); MIK-1, Mikawa Bay 1, Japan (dotted); and (b) mean allelic uniqueness (rarefacted number of private alleles per locus) among European localities only; bar colours display geographic grouping as indicated in plot (a). Error bars indicate the SD of arithmetic means. Means not significantly different from one another share the same small letters ( $a$ and $b$, respectively) above the error bars $(\alpha=0.05)$.

0.0243 , respectively), whereas a comparison between Taiwan and northern samples was not $(P=0.0637)$.

Averaged over all markers, no single European or North American location topped one private allele per locus (Table S1) and the frequencies observed for private alleles mirrors the trend observed in allelic richness. Again, the northeastern European samples had the highest proportion of unique alleles, followed by the Brittany and finally the southwestern European samples (Fig. 5b). One informative microsatellite allele was ' 231 ' at locus AcrCT54, which shows relatively high frequencies in southern locations LOI $(12.0 \%)$, ORI (5.88\%), RHO (11.3\%) and TIB (12.9\%), but is not found in Taiwan and in the other European locations, except the Irish population SHA (2.78\%). Since correction for null alleles cannot be performed in these tests (Chapuis \& Estoup 2007), we did a sensitivity analysis using the two different sets of null-allele-affected markers 
(Fig. S6a and b, Supplementary material). The unique alleles declined from northern to southern European sampling localities in both sets, although some of the populations followed slightly different trends. In sum, null alleles do not appear to have changed the overall pattern.

Isolation-by-distance and genetic barriers. Neither standardized nor unstandardized $\theta_{\mathrm{ST}}$ values correlated significantly with geographic distances (Table 3). However, using the $\rho_{\text {ST }}$ estimator (Rousset 1996), a Mantel test revealed a highly significant isolation-by-distance (IBD) pattern in the European Anguillicola crassus populations (Table 3). This finding was robust against the influences of null alleles. As the estimator for population differentiation is based on the stepwise mutation model (SMM), it appears to be most suitable given our microsatellite data (Ellegren 2004). To explicitly test if the IBD pattern is caused by phylogeographic breaks in the data, the pairwise null-corrected $\rho_{\mathrm{ST}(\mathrm{ENA})}$ estimates were compared to the triangulated geographic data using Monmonier's (1973) algorithm in BARRIERS version 2.2 (Manni et al. 2004). Importantly, the same major phylogeographic breaks became apparent that are suggested when combining results from STRUCTURE, the clines in allelic richness and distinctiveness and the population distance tree. Placing barriers one-by-one, geographic groupings were separated from the remaining locations in the following order: (i) Mediterranean Sea (RHO, TIB); (ii) Baltic Sea (OER, ALA); (iii) Bay of Biscay (ORI, LOI); (iv) Ireland (SHA, NEA); and (v) the Brittany samples (FRE, VIL) which left Great Britain (SLP) ungrouped. This last step suggests that there might be a migratory link connecting these historically and geographically closely related areas.

\section{Mitochondrial DNA}

Nucleotidic and haplotypic diversity. Fifty COI haplotypes were found among the 419 individuals typed. The data set contained 55 segregating sites (and 62 mutational changes) for a sequence length of $552 \mathrm{bp}$, of which 35 were parsimony-informative. Most of the substitutions were in the third codon position but nine out of 62 resulted in amino acid changes. One replacement took place at site 32 (A to $\mathrm{G}$ ), a first codon position, resulting in a change from methionine to valine in a branch leading to five remote Mikawa Bay haplotypes (Fig. 6). This group included MIK08, MIK29 and MIK30 which also appeared as outliers in the FCA. Another replacement occurred at position 164 ( $\mathrm{C}$ to $\mathrm{T}$ ) and induced a lysine to phenylalanine change; this mutational step is shared by $25 \%$ of the individuals from the Shannon River and Lake Neagh, emphasizing their common ancestry.

Haplotype diversity $(h)$ varied considerably among locations (Table S3, Supplementary material), but only one native and two invasive geographic populations were far below 0.5 (MIK-2, 0.228; STJ, 0.232; RHO, 0.384). The three highest absolute values were all found in indigenous populations (MIK-1, 0.970; YAM, 0.905 and KAO, 0.814). Moreover, estimated values for nucleotide diversities were below 0.005 for all locations, except the native Asian MIK-1. In combination, values of $h>0.5$ and $\pi<0.005$, respectively, are interpreted as signs of recent population expansion after a bottleneck restrained population sizes (Grant \& Bowen 1998), because large populations sizes support the maintenance of (newly arisen) mutations of low frequencies. Based on Fu's Fs (Fu 1997), however, only the Taiwanese sample of KAO showed a significantly negative value of -7.8 .

Population differentiation. $\theta_{\mathrm{ST}}$ values inferred from mitochondrial DNA sequences were 3.9 times higher than estimates for nuclear-derived microsatellites, as is expected due to the fourfold higher effective size of nuclear markers compared to mitochondrial loci (Table 2). A positive correlation between both estimates was observed $(r=0.69)$. Again, southern populations were genetically more similar to one another than to other populations, and no single pairwise comparison was significantly different after Bonferroni correction. As for the microsatellite data, the local northern clusters became apparent [SHA-NEA, $\theta_{\mathrm{ST}}=0.00$, not significant (n.s.); OER-ALA, $\theta_{\mathrm{ST}}=0.055$, n.s.]. The $\theta_{\mathrm{ST}}$ value between SLP and NEA of 0.29 indicated high differentiation and may reflect drift effects for SLP. The differences between north and south were more pronounced with $\theta_{\mathrm{ST}}$ values up to 0.62 between ALA and RHO. Based on $\theta_{\mathrm{ST}}$ values, the Taiwanese population KAO is not distinguishable from the Baltic population $\operatorname{ALA}\left(\theta_{\mathrm{ST}}=0.011\right.$, n.s.), but more differentiated from OER, VIL, SHA and $\operatorname{NEA}\left(\theta_{\mathrm{ST}}=0.093-0.098\right)$. Among Asian populations, Japanese samples from YAM and MIK-1 are the least differentiated native populations $\left(\theta_{\mathrm{ST}}=0.125\right.$, n.s. $)$.

Haplotype partition. The haplotype network shows an overall star-like pattern hinting towards a recent, common expansion of the native Taiwanese population, while Japanese individuals from MIK and YAM are more evenly spread (Fig. 6), favouring an older age of these populations. Excluding singleton haplotypes, there are three unique northern haplotypes, compared to one southern and no unique Brittany haplotype. In addition, northern samples contained twice as many haplotypes (22 out of 127) when compared to either the southern (10 out of 126) or the Brittany samples (five out of 61). All major southern haplotypes are present in northeastern Europe, Brittany and Taiwan, but not the other way around. A striking feature is that 29 out of 32 North American (STJ) individuals share the unique MIK-2 haplotype $\left(\theta_{\mathrm{ST}}=0.025\right.$, n.s. $)$ indicating that the US samples most likely originated directly from a Japanese introduction rather than from a 


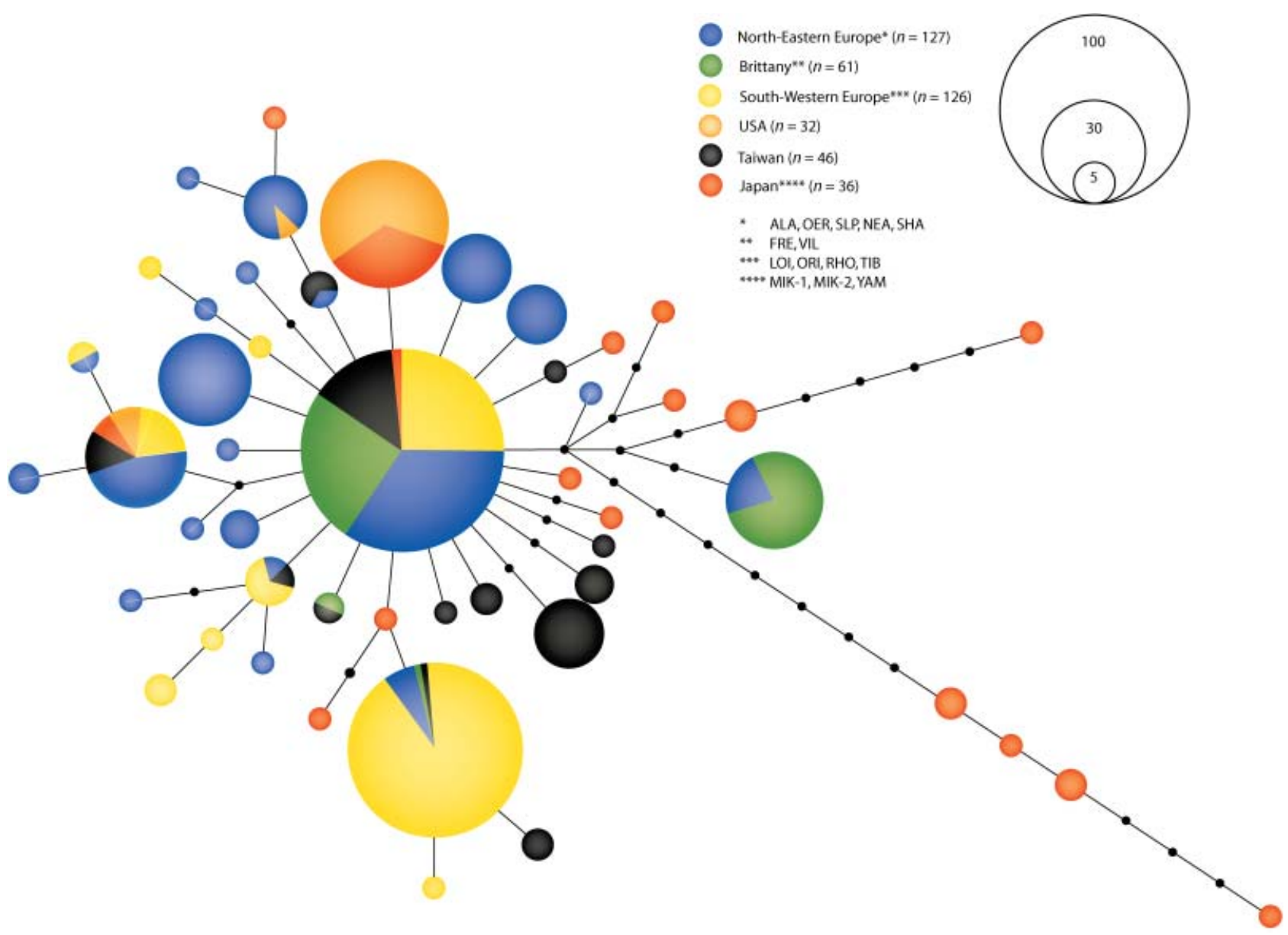

Fig. 6 Minimum-spanning haplotype network of mitochondrial COI haplotypes. Circles represent one mutational change toward either connection; the areas of circles and circle sections are directly proportional to the number of individuals sharing the same haplotype sequence. Unsampled haplotypes are represented by small black dots. All haplotypes sequences have been submitted to GenBank (Accession nos. EU376536-EU376954).

primary colonization from Taiwan or a secondary jump event from Europe.

Analysis of molecular variance. When populations were grouped according to STRUCTURE and FCA (northeast, Brittany, southwest), most of the genetic diversity was found within populations $(65.36 \%)$. In contrast to microsatellite data, a larger diversity was found among groups $(26.50 \%$; $P=0.003$ ) and less among populations within groups $(8.14 \%)$. Among groups genetic structure became apparent: $\Phi_{\mathrm{ST}}=0.346 ; \Phi_{\mathrm{SC}}=0.111 ;$ and $\Phi_{\mathrm{CT}}=0.265$.

\section{Discussion}

\section{Inferring the number and origin of invasions}

Anguillicola crassus shows a mild macrogeographic population structure in the European eel and there is a moderate genetic separation between southwestern and northeastern European samples. Although we detected the presence of null alleles in at least two out of the seven markers, correction did not alter the initial results upon close scrutiny. Moreover, using subsets of markers, the same trend was revealed and thus fostered the robustness of our inference. Three lines of support indicate that random genetic drift in the nematode's new ranges in Europe, rather than multiple independent invasions from Asia have generated this nuclear genetic structure. First, mixing of distinct imports upon or shortly after arrival would have artificially enlarged the gene pool (Hartl \& Clark 1997). This would have increased the diversity in Europe relative to single Asian populations. Yet, this is not the case, since locus-wide microsatellite diversity for any colonizer population is below the values observed in the native Taiwanese (KAO) and Japanese (MIK-1) populations. Second, in a nuclear phylogenetic context, local samples in the southwest and Brittany form distinct monophyletic groups with high bootstrap support and both are nested 
within the northeastern group, suggesting a common origin of all European samples. Third, assuming a one-dimensional stepping-stone model of migration (Hartl \& Clark 1997), we identified a decline in both nuclear rarefacted (private) allelic diversity, and mitochondrial haplotype diversity from the putative source of invasion in northern Europe (Neumann 1985) to the extant southern distribution areas of the Mediterranean Sea. The Brittany populations in the centre of our sampling range are always intermediate in that respect. Consequently, an isolation-by-distance pattern was detected for the microsatellite data. This overall pattern of decreasing diversity might have been accelerated by the north-to-south increase of generation times from approximately one to two generations per year.

Our results further suggest that the source populations of the invader differed between the New and the Old World. Based on the nuclear markers, the Bayesian likelihood estimation groups North American individuals together with two out of three Japanese samples. Furthermore, this grouping is supported by a population tree, based on chord distances, with high bootstrap support. Finally, the majority of North American A. crassus specimens (29 out of 32) share the most common Japanese haplotype found exclusively in MIK-2, which is not present either in Europe or Taiwan.

Although we found a considerable nuclear genetic overlap among the Taiwanese (KAO) and northwestern European samples on the one hand, and the Japanese sample MIK-1 on the other hand, we can assume a common Taiwanese origin for European populations as has been previously proposed based on eel import data (Koops \& Hartmann 1989). Whereas there is a high degree of nuclear genetic overlap among Japanese MIK-1 and Taiwanese KAO samples, the opposite is true for mitochondrial haplotype data. This somewhat contradictory finding appears plausible when recent admixture among Asian regions is assumed. Intensive eel trading activity around Mikawa Bay is reported in the literature (Usui 1991) and our assumption is further supported by the sampling of one silver eel carrying different population of nematodes (MIK-2) as compared to the other nine infected eels caught in Mikawa Bay (MIK-1). MIK-2 shared most affinities with a second southern Japanese sample from Yamaguchi (YAM). Importantly, the indigenous Taiwanese population shows consistent signatures of recent expansion based on mitochondrial haplotype partition, which is in contrast to Japanese samples. This is supported by a significantly negative $F_{\mathrm{S}}$ test for KAO (Fu 1997) and a combination of high haplotypic $(h>0.5)$ and low nucleotidic $(\pi>0.005)$ diversities. When rooting the mitochondrial haplotype tree with the putative sister species Anguillicola globiceps (data not shown) five MIK1 samples appear basal to the remainder of the A. crassus data set, which suggests that the Taiwanese population was derived from an indigenous Japanese one, predating recent eel trading activities.

\section{Aspects of European biogeography}

Surprisingly, in the context of eel host trades, the population structure of $A$. crassus in Europe reflects trends already observed in marine invertebrates (Wilke \& Pfenninger 2002; Luttikhuizen et al. 2003; Roman \& Palumbi 2004). The three geographic clusters identified with the Bayesian tool (the northeast, the Brittany and southwest) are reminiscent of the Boreal-Lusitanian break between northern and western Europe along the English Channel, as described by Briggs $(1970,1974)$ for marine benthic zoogeographic regions. We interpret our finding in terms of the important influence of host movement and dispersal on the parasite population structure (Blouin et al. 1995; Blouin et al. 1999; Hawdon et al. 2001).

Since the main eel trading countries were affected first, the change and expansion of trading routes can be held responsible for the rapid spread of Anguillicola in the 1980s (Kirk 2003). While England was already affected through intensive eel trade by 1987 (Kennedy \& Fitch 1990), it took another 11 years for the Irish eel stocks to be infected, after eels from England were stocked there (Evans \& Matthews 1999). This event is apparent from our data, as Ireland and England share nuclear genetic affinities. Given the vast distribution area of extant populations both in the northern and southern parts of Europe, the maintenance of high levels of gene flow seems to be kept by recurrent long-range eel host transport within regions. In the northeast, this is consistent with reports on intensive restocking activities (Dekker 2003). This in turn contributes to keep a considerable amount of allelic diversity within these regions.

The presence of a local population of A. crassus in Brittany, which is genetically intermediate, suggests that occasional natural migration or passive dispersal of fish hosts have influenced the genetic make-up at this edge. Two lines of argument support this hypothesis. First, eel recruitment occurs naturally in Brittany [FISHPASS, Rennes (F), personal communication], and thus, introduction of the parasite by eel stocking seems improbable. Second, natural barriers to intermediate copepod hosts clearly separate Boreal and Lusitanian zones due to oceanic currents and strict temperature and salinity clines (Briggs 1974). This leaves natural fish host migrations as source of dispersal. The pronounced natural barriers in Europe are highlighted by the BARRIERs tool, which groups major geographic units that are separated from other such groups, namely the Mediterranean from the Baltic Sea, and farther the Bay of Biscay from Ireland and the Brittany region. Interestingly, Brittany and Great Britain display the weakest genetic break among all geographic neighbours (Manni et al. 2004).

Alternatively, the biogeographic partitioning of A. crassus would mirror that of its marine benthic invertebrate hosts 
due to certain selective influences which cannot be measured with neutral genetic markers. Since the main isolating forces underlying Briggs's (1974) break are oceanic currents and temperature gradients along the European coastlines, the nematode's dependence on and acquisition of local invertebrate hosts, which follow Briggs's biogeographic break (Briggs 1974), could have maintained population genetic structure of $A$. crassus in Europe due to differential survival depending on the predominant copepod host communities. Although this scenario is highly speculative, it may serve as a working hypothesis for future studies. Importantly, it has been previously suggested that parasite population genetic structure could serve as proxy for inference of its host's structure (Wirth et al. 2005; Nieberding \& Olivieri 2007). Thus, we can assume that population structure in parasites with indirect life cycles reflects a combination of intermediate, paratenic and final host migrations, which can be strongly influenced by humandriven host movement.

\section{Perspectives}

As Strayer et al. (2006) pointed out, a study on invasive species, which 'randomly' picks a given period in time, clearly delivers only a glimpse of an ongoing process. It is apparent from our data that many local populations of the nematode have not yet reached migration-drift equilibrium due to the relatively short time span between first observation and establishment in the new host. The observed swimbladder infestations are suggested to compromise successful completion of the eel host's spawning migration (Palstra et al. 2007; Lefebvre et al. 2007); thus, adaptations on the host's side will evolve rather rapidly. Rapid evolution due to parasite invasion has been previously shown for a vast range of phyla (Cox 2004). In the North Atlantic eel's case, the MHC class II B loci involved in the recognition of extra-cellular parasites and other genes related to acquired immunity are likely candidates for further investigations in this ongoing arms race. Loci with immunological function are expected to vary among species inhabiting different habitats with different parasite and pathogen pressures (displayed in benthic and pelagic sticklebacks, e.g. in lakes from the Plöner Seenplatte in northern Germany; Wegner et al. 2003). That is to say, the eels might be quite homogeneous in terms of neutral markers, although genetic diversity at loci under balancing selection could reveal higher heterogeneity and thus the potential to acquire resistance to the nematode. Evidence gathered from well-studied sites in Europe (Audenaert et al. 2003; Lefebvre \& Crivelli 2004) shows stabilization and even a slight decline in nematode abundance and intensities in recent years, possibly reflecting increased resistance towards these parasites in the long term.

\section{Acknowledgements}

We owe thanks to all our collaborators who directly contributed specimens or otherwise helped with sampling (Table 1), including Mathias Wegner, and Ahmed Yahyaoui. We thank Pascale Chesselet, Helen Gunter, Kathryn Elmer, Jody Shields and three reviewers for stimulating comments on the manuscript. This work was supported by grants from the Deutsche Forschungsgemeinschaft to T.W. and A.M., and from the University Konstanz to A.M., as well as a studentship by the Landesgraduiertenförderung BadenWürttemberg to S.W.

\section{References}

Anderson JD, Williams-Blangero S, Anderson TJ (2003) Spurious genotypes in female nematodes resulting from contamination with male DNA. Journal of Parasitology, 89, 1232-1234.

Audenaert V, Huyse T, Goemans G, Belpaire C, Volckaert F (2003) Spatio-temporal dynamics of the parasitic nematode Anguillicola crassus in Flanders, Belgium. Diseases of Aquatic Organisms, 56, 223-233.

Barse AM, McGuire SA, Vinores MA, Eierman LE, Weeder JA (2001) The swimbladder nematode Anguillicola crassus in American eels (Anguilla rostrata) from middle and upper regions of Chesapeake Bay. Journal of Parasitology, 87, 1366-1370.

Behrmann-Godel J, Eckmann R (2003) A preliminary telemetry study of the migration of silver European eel (Anguilla anguilla L.) in the River Mosel, Germany. Ecology of Freshwater Fish, 12, 196-202.

Blouin MS, Liu J, Berry RE (1999) Life cycle variation and the genetic structure of nematode populations. Heredity, 83, 253-259.

Blouin MS, Yowell CA, Courtney CH, Dame JB (1995) Host movement and the genetic structure of populations of parasitic nematodes. Genetics, 141, 1007-1014.

Briggs JC (1970) A faunal history of the North Atlantic Ocean. Systematic Zoology, 19, 19-34.

Briggs JC (1974) Marine Zoogeography, 1st edn. McGraw-Hill, New York.

Bruford MW, Hanotte O, Brookfield JFY, Burke T (1992) Multi-locus and single-locus DNA fingerprinting. In: Molecular Analysis of Populations (ed. Hoelzel AR), pp. 283-336. Oxford University Press, New York.

Bush AO, Lafferty KD, Lotz JM, Shostak AW (1997) Parasitology meets ecology on its own terms: Margolis et al. revisited. Journal of Parasitology, 83, 575-583.

Bush AO, Fernández JC, Esch GW, Seed JR (2001) Parasitism: the Diversity and Ecology of Animal Parasites. Cambridge University Press, Cambridge, UK.

Castonguay M, Hodson PV, Moriarty C, Drinkwater KF, Jessop BM (1994) Is there a role of ocean environment in American and European eel decline? Fisheries Oceanography, 3, 197-203.

Cavalli-Sforza LL, Edwards AW (1967) Phylogenetic analysis. Models and estimation procedures. American Journal of Human Genetics, 19, Part I, 233-257.

Chapuis M-P, Estoup A (2007) Microsatellite null alleles and estimation of population differentiation. Molecular Biology and Evolution, 24, 621-631.

Clement M, Posada D, Crandall KA (2000) TCs: a computer program to estimate gene genealogies. Molecular Ecology, 9, 1657-1659.

Colautti RI, MacIsaac HJ (2004) A neutral terminology to define 'invasive' species. Diversity and Distributions, 10, 135-141. 
Cox GW (2004) Alien Species and Evolution. Island Press, Washington, D.C.

Criscione CD, Blouin MS (2004) Life cycles shape parasite evolution: comparative population genetics of salmon trematodes. Evolution, 58, 198-202.

Criscione CD, Poulin R, Blouin MS (2005) Molecular ecology of parasites: elucidating ecological and microevolutionary processes. Molecular Ecology, 14, 2247-2257.

Criscione CD, Cooper B, Blouin MS (2006) Parasite genotypes identify source populations of migratory fish more accurately than fish genotypes. Ecology, 87, 823-828.

Dawson KJ, Belkhir K (2001) A Bayesian approach to the identification of panmictic populations and the assignment of individuals. Genetical Research, 78, 59-77.

Dekker W (2003) Did lack of spawners cause the collapse of the European eel, Anguilla anguilla? Fisheries Management and Ecology, 10, 365-376.

Egusa S (1979) Notes on the culture of the European eel (Anguilla anguilla L.) in Japanese eel-farming ponds. In: Eel Research and Management. Rapports et procès-verbaux des réunions. Conseil Permanent International pour l'Exploration de la Mer (ed. Thurow F), pp. 51-58.

Ellegren H (2004) Microsatellites: simple sequences with complex evolution. Nature Reviews Genetics, 5, 435-445.

Evanno G, Regnaut S, Goudet J (2005) Detecting the number of clusters of individuals using the software STRUCTURE: a simulation study. Molecular Ecology, 14, 2611-2620.

Evans DW, Matthews MA (1999) Anguillicola crassus (Nematoda, Dracunculoidea): first documented record of this swimbladder parasite in Ireland. Journal of Fish Biology, 55, 665-668.

Excoffier L, Smouse P, Quattro J (1992) Analysis of molecular variance inferred from metric distances among DNA haplotypes: applications to human mitochondrial DNA restriction data. Genetics, 131, 479-491.

Excoffier L, Laval G, Schneider S (2005) ARLEQUIN version 3.0: an integrated software package for population genetics data analysis. Evolutionary Bioinformatics Online, 1, 47-50.

Falush D, Stephens M, Pritchard JK (2003) Inference of population structure using multilocus genotype data: linked loci and correlated allele frequencies. Genetics, 164, 1567-1587.

Falush D, Stephens M, Pritchard JK (2007) Inference of population structure using multilocus genotype data: dominant markers and null alleles. Molecular Ecology Notes, 7, 574-578.

Folmer O, Black M, Hoeh W, Lutz R, Vrijenhoek R (1994) DNA primers for amplification of mitochondrial cytochrome $c$ oxidase subunit I from diverse metazoan invertebrates. Molecular Marine Biology and Biotechnology, 3, 294-299.

Freeman AS, Byers JE (2006) Divergent induced responses to an invasive predator in marine mussel populations. Science, 313, 831- 833.

Fu XY (1997) Statistical tests of neutrality of mutations against population growth, hitchhiking, and background selection. Genetics, 147, 915-925.

Gollock MJ, Kennedy CR, Brown JA (2005) Physiological responses to acute temperature increase in European eels Anguilla anguilla infected with Anguillicola crassus. Diseases of Aquatic Organisms, 64, 223-228.

Grant W, Bowen B (1998) Shallow population histories in deep evolutionary lineages of marine fishes: insights from sardines and anchovies and lessons for conservation. Journal of Heredity, 89, 415-426.

Hartl DL, Clark AG (1997) Principles of Population Genetics, 3rd edn. Sinauer Associates, Sunderland, Massachusetts.
Hawdon JM, Li T, Zhan B, Blouin MS (2001) Genetic structure of populations of the human hookworm, Necator americanus, in China. Molecular Ecology, 10, 1433-1437.

Hendry A, Wenburg J, Bentzen P, Volk E, Quinn T (2000) Rapid evolution of reproductive isolation in the wild: evidence from introduced salmon. Science, 290, 516-518.

Huelsenbeck JP, Andolfatto P (2007) Inference of population structure under a Dirichlet process model. Genetics, 175, 1787-1802.

Kalinowski ST (2005) HP-RARE 1.0: a computer program for performing rarefaction on measures of allelic richness. Molecular Ecology Notes, 5, 187-189.

Kennedy CR, Fitch DJ (1990) Colonization, larval survival and epidemiology of the nematode Anguillicola crassus, parasitic in the eel, Anguilla anguilla, in Britain. Journal of Fish Biology, 36, 117-131.

Kettle A, Haines K (2006) How does the European eel (Anguilla anguilla) retain its population structure during its larval migration across the North Atlantic Ocean? Canadian Journal of Fisheries and Aquatic Sciences, 63, 90-106.

Kirk R (2003) The impact of Anguillicola crassus on European eels. Fisheries Management and Ecology, 10, 385-394.

Kirk RS, Kennedy CR, Lewis JW (2000a) Effect of salinity on hatching, survival and infectivity of Anguillicola crassus (Nematoda: Dracunculoidea) larvae. Diseases of Aquatic Organisms, 40, 211-218.

Kirk RS, Lewis JW, Kennedy CR (2000b) Survival and transmission of Anguillicola crassus Kuwahara, Niimi \& Itagaki, 1974 (Nematoda) in seawater eels. Parasitology, 120, 289-295.

Knights B (2003) A review of the possible impacts of long-term oceanic and climate changes and fishing mortality on recruitment of anguillid eels of the Northern Hemisphere. The Science of the Total Environment, 310, 237-244.

Knopf K (2006) The swimbladder nematode Anguillicola crassus in the European eel Anguilla anguilla and the Japanese eel Anguilla japonica: differences in susceptibility and immunity between a recently colonized host and the original host. Journal of Helminthology, 80, 129-136.

Koops H, Hartmann F (1989) Anguillicola infestations in Germany and in German eel imports. Journal of Applied Ichthyology, 1, 41-45.

Lee CE (2002) Evolutionary genetics of invasive species. Trends in Ecology \& Evolution, 17, 386-391.

Lefebvre F, Contournet P, Crivelli AJ (2007) Interaction between severity of the infection by the nematode Anguillicola crassus and the tolerance to hypoxia in the European eel Anguilla anguilla. Acta Parasitologica, 52, 171-175.

Lefebvre F, Crivelli AJ (2004) Anguillicolosis: dynamics of the infection over two decades. Diseases of Aquatic Organisms, 62, 227-232.

Licek E, Moosbeckhofer R, Pechhacker H (2004) Varroa destructor, a parasitic mite of the honeybee (Apis mellifera) - a survey of biology and control strategies. Wiener Tierärztliche Monatsschrift, 91, 311-316.

Luttikhuizen PC, Drent J, Baker AJ (2003) Disjunct distribution of highly diverged mitochondrial lineage clade and population subdivision in a marine bivalve with pelagic larval dispersal. Molecular Ecology, 12, 2215-2229.

Maes GE, Volckaert FAM (2002) Clinal genetic variation and isolation by distance in the European eel Anguilla anguilla (L.). Biological Journal of the Linnean Society, 77, 509-521.

Maes GE, Pujolar JM, Hellemans B, Volckaert FA (2006) Evidence for isolation by time in the European eel (Anguilla anguilla L.). Molecular Ecology, 15, 2095-2107.

Manni F, Guérard E, Heyer E (2004) Geographic patterns of (genetic, morphologic, linguistic) variation: how barriers can be 
detected by using Monmonier's algorithm. Human Biology, 76, 173-190.

Mantel N (1967) The detection of disease clustering and a generalized regression approach. Cancer Research, 27, 209-220.

McCoy KD, Boulinier T, Tirard C, Michalakis Y (2003) Hostdependent genetic structure of parasite populations: differential dispersal of seabird tick host races. Evolution, 57, 288-296.

Meirmans PG (2006) Using the AMova framework to estimate a standardized genetic differentiation measure. Evolution, 60, 2399-2402.

Monmonier M (1973) Maximum-difference barriers: an alternative numerical regionalization method. Geographical Analysis, 3, 245-261.

Moravec F, Taraschewski H (1988) Revision of the genus Anguillicola Yamaguti, 1935 (Nematoda: Anguillicolidae) of the swimbladder of eels, including descriptions of two new species, A. novaezelandiae sp.n. and A. papernai sp.n. Folia Parasitologica, 35, 125-146.

Münderle M et al. (2006) Occurrence of Anguillicola crassus (Nematoda: Dracunculoidea) in Japanese eels Anguilla japonica from a river and an aquaculture unit in SW Taiwan. Diseases of Aquatic Organisms, 71, 101-108.

Nei M (1978) Estimation of average heterozygosity and genetic distance from a small number of individuals. Genetics, 89, 583-590.

Nei M (1987) Molecular Evolutionary Genetics, 1st edn. Columbia University Press, New York.

Nei M, Tajima F (1981) DNA polymorphism detectable by restriction endonucleases. Genetics, 97, 145-163.

Neumann W (1985) Schwimmblasenparasit Anguillicola bei Aalen. Fischer and Teichwirt, 11, 322.

Nieberding CM, Olivieri I (2007) Parasites: proxies for host genealogy and ecology? Trends in Ecology \& Evolution, 22, 156-165.

van Oosterhout C, Hutchinson WF, Wills DPM, Shipley P (2004) MICRO-CHECKER: software for identifying and correcting genotyping errors in microsatellite data. Molecular Ecology Notes, 4, 535-538.

Palstra AP, Heppener DFM, van Ginneken VJT, Székely C, van den Thillart GEEJM (2007) Swimming performance of silver eels is severely impaired by the swim-bladder parasite Anguillicola crassus. Journal of Experimental Marine Biology and Ecology, 352, 244-256.

Pella J, Masuda M (2006) The Gibbs and split-merge sampler for population mixture analysis from genetic data with incomplete baselines. Canadian Journal of Fisheries and Aquatic Sciences, 63, 576-596.

Penner GA, Bush A, Wise Ret al. (1993) Reproducibility of random amplified polymorphic DNA (RAPD) analysis among laboratories. PCR Methods and Applications, 2, 341-345.

Pimentel D et al. (2001) Economic and environmental threats of alien plant, animal and microbe invasions. Agriculture, Ecosystems and Environment, 84, 1-20.

Pimentel D, ed. (2002) Biological invasions. Economic and Environmental Costs of Alien Plant, Animal, and Microbe Species. CRC Press, Boca Raton, Florida.

Posada D, Crandall KA (1998) MODELTEST: testing the model of DNA substitution. Bioinformatics, 14, 817-818.

Pritchard JK, Stephens M, Donnelly P (2000) Inference of population structure using multilocus genotype data. Genetics, 155, 945-959.

Rahhou I, Morand S, Lecomte-Finiger R, Sasal P (2005) Biogeographical relationships of the eel parasite Anguillicola crassus revealed by random amplified polymorphic DNA markers (RAPDs). Bulletin Français de la Pêche et de la Pisciculture, 378-379, 87-98.
Raymond M, Rousset F (1995) GENEPOP version 1.2.: population genetics software for exact tests and ecumenicism. Journal of Heredity, 86, 248-249.

Roman J, Palumbi SR (2004) A global invader at home: population structure of the green crab, Carcinus maenas, in Europe. Molecular Ecology, 13, 2891-2898.

Rosenberg NA (2004) DISTRUCT: a program for the graphical display of population structure. Molecular Ecology Notes, 4, 137-138.

Rosenberg MS (2008) PASSAGE: Pattern Analysis, Spatial Statistics and Geographic Exegesis, Version 2. http://www.passagesoftware.net.

Rousset F (1996) Equilibrium values of measures of population subdivision for stepwise mutation processes. Genetics, 142, 1357-1362.

Saitou N, Nei M (1987) The neighbor-joining method: a new method for reconstructing phylogenetic trees. Molecular Biology and Evolution, 4, 406-425.

Sakai AK, Allendorf FW, Holt JS et al. (2001) The population biology of invasive species. Annual Review of Ecology and Systematics, 32, 305-332.

Sasal P, Taraschewski H, Valade P, Grondin H, Wielgoss S, Moravec F (2008) Parasite communities in eels of the Island of Reunion (Indian Ocean): a lesson in parasite introduction. Parasitology Research, 102, 1343-1350.

Slatkin M (1995) A measure of population subdivision based on microsatellite allele frequencies. Genetics, 139, 457-462.

Sokal RR, Rohlf FJ (1995) Biometry, 3rd edn. W.H. Freeman, New York. Strayer DL, Eviner VT, Jeschke JM, Pace ML (2006) Understanding the long-term effects of species invasions. Trends in Ecology and Evolution, 21, 645-651.

Swofford DL (2003) PAUP* - Phylogenetic Analyses Using Parsimony ( ${ }^{*}$ and Other Methods), Version 10. Sinauer Associates, Sunderland, Massachusetts.

Taraschewski H (2006) Hosts and parasites as aliens. Journal of Helminthology, 80, 99-128.

Tesch F-W (2003) The Eel, 3rd edn. Blackwell Publishing, Oxford, UK.

Thomas K, Ollevier F (1992) Paratenic hosts of the swimbladder nematode Anguillicola crassus. Diseases of Aquatic Organisms, 13, 165-174.

Thomas K, Ollevier F (1993) Hatching, survival, activity and penetration efficiency of second-stage larvae of Anguillicola crassus (Nematoda). Parasitology, 107, 211-217.

Usui A (1991) Eel Culture, 2nd edn. Blackwell Scientific Publishing, Cambridge, Massachusetts.

Wegner KM, Kalbe M, Kurtz J, Reusch TBH, Milinski M (2003) Parasite selection for immunogenetic optimality. Science, 301, 1343.

Weir BS, Cockerham CC (1984) Estimating F-statistics for the analysis of population structure. Evolution, 38, 1358-1370.

Wielgoss S, Sanetra M, Meyer A, Wirth T (2007) Isolation and characterization of short tandem repeats in an invasive swimbladder nematode, parasitic in Atlantic freshwater eels, Anguillicola crassus. Molecular Ecology Notes, 7, 1051-1053.

Wilke T, Pfenninger M (2002) Separating historic events from recurrent processes in cryptic species: phylogeography of mud snails (Hydrobia spp.). Molecular Ecology, 11, 1439-1451.

Wirth T, Bernatchez L (2001) Genetic evidence against panmixia in the European eel. Nature, 409, 1037-1040.

Wirth T, Bernatchez L (2003) Decline of North Atlantic eels: a fatal synergy? Proceedings of the Royal Society B: Biological Sciences, 270, 681-688.

Wirth T, Meyer A, Achtman M (2005) Deciphering host migrations and origins by means of their microbes. Molecular Ecology, 14, 3289-3306. 
Sébastien Wielgoss is a $\mathrm{PhD}$ student delving into population genetics and phylogeography in parasites and their hosts. Horst Taraschewski is a parasitologist with major interest in the hostparasite associations of species lacking co-evolution due to the transcontinental displacement of one species into the range of the other. Axel Meyer is an evolutionary geneticist interested in the ecological, developmental and genomic aspects of speciation. Thierry Wirth is a population geneticist with a special interest in the evolution of teleost fish species. His research covers the characterization of population genetic structure in anguillid eel populations using microsatellite markers.

\section{Supplementary material}

The following supplementary material is available for this article:

Fig. S1 (a) Likelihood probabilities $\ln P(D)$ representing 10 independent runs for each examined number of assumed population clusters $(K)$, analysed in STRUCTURE version 2.2 (Pritchard et al. 2000). (b) Subsequent statistical evaluation of the likelihood values for a given number of assumed population clusters $(K)$ using the ad hoc statistic $\Delta K$ proposed by Evanno et al. (2005). (c) and (b) are analogous to (a) and (b) having derived from five independant runs using a null-allele-corrected dataset.

Fig. S2 Individual-based cluster representation based on Bayesian inference of population structure for two scenarios (a-d) $K=2$ and (e-h) $K=4$.

Fig. S3 Factorial component analysis representing the first three orthogonal axes of variation ranked by informativeness.
Fig. S4 Neighbour-joining (NJ) phenogram summarizing CavalliSforza \& Edwards' (1967) $D_{\mathrm{CE}}$ chord distances without null-allele correction among 12 invasive and three native populations.

Fig. S5 Box plot representation of local allelic richness (rarefacted number of alleles per locus) between European, North American and Asian locations.

Fig. S6 Box plot representation of mean allelic uniqueness for (a) the four markers deviating from HWE (AcrCT29, AcrCT53, AcrCT103, AcrCA102); and (b) three markers not deviating from HWE (AcrCT04, AcrCT27, AcrCT54).

Table S1 Allele counts and rarefacted allelic richness and diversity ( $n=24$ genes) as measured for all microsatellite loci.

Table S2 Unbiased expected $\left(H_{\mathrm{E}}\right)$ and observed $\left(H_{\mathrm{O}}\right)$ heterozygosities for single loci, including respective inbreeding coefficients $\left(F_{\mathrm{IS}}\right)$ and probabilities $(P)$ of exact tests for Hardy-Weinberg equilibrium for all locations.

Table S3 Measures of mitochondrial DNA diversity observed in cytochrome c oxidase subunit I (COI) of Anguillicola crassus from 16 locations in Europe, North America and putative source populations from East Asia. Haplotype gene diversity $h$ and nucleotide diversity $\pi$ contain standard deviations of each estimate.

This material is available as part of the online article from: http://www.blackwell-synergy.com/doi/abs/10.1111/ j.1365-294X.2008.03855.x

(This link will take you to the article abstract).

Please note: Blackwell Publishing are not responsible for the content or functionality of any supplementary materials supplied by the authors. Any queries (other than missing material) should be directed to the corresponding author for the article. 